\title{
صناديق الثروة السيادية لدول الخليج العربية بين الاستدامة والتحديات المستمرة الدولة الدادة
}

\section{Sovereign Wealth Funds in the Gulf Arab States: Sustainability and Ongoing Challenges}

تهتم الدراسة بتحليل استدامة الصناديق السيادية في دول الخليج العربية، وتعرض التحديات التي تواجهها،

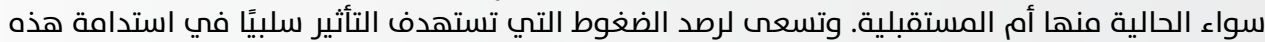

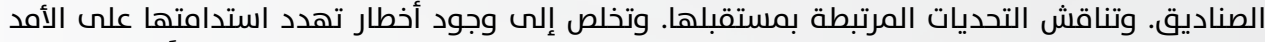

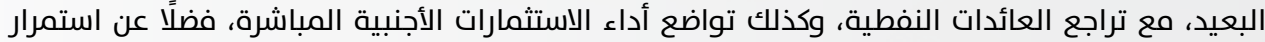

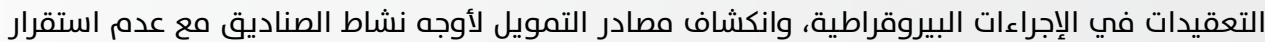

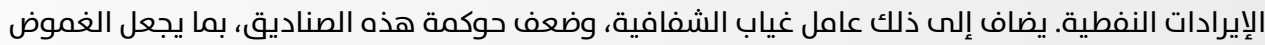

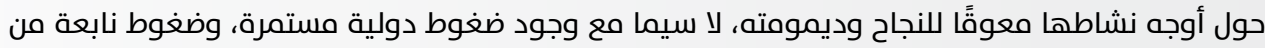

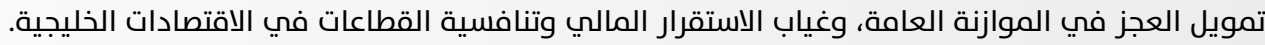

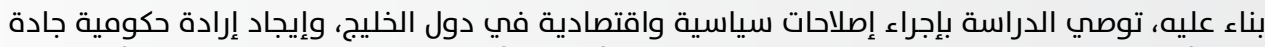
من شأنها تعزيز البرامج المالية والاستثمارية، وتحقيق أهداف تأسيس الصناديق السيادية؛ من أجل تنوية إديع

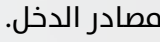
كلمات مفتاحية: دول الخليج العربية، الصناديق السيادية، استدامة الموارد، الشفافية، الفاعلية الحكومية،

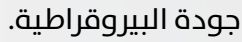

This study analyzes the sustainability of sovereign wealth funds (SWFs) in the Gulf Cooperation Council (GCC) countries and monitors pressures that may negatively impact SWFs' sustainability. The challenges associated with the future of these funds are also discussed. The study concludes that, as oil revenues fluctuate and decline and foreign direct investment shrinks, there are numerous threats to these funds' sustainability. Additional threats include complicated bureaucratic procedures, the absence of transparency, and weak Gulf SWF governance. Accordingly, the study recommends political and economic reforms in the Gulf states and governmental commitment to promoting financial and investment programs and achieving SWFs' objectives of diversifying sources of income.

Keywords: Gulf Arab States, Sovereign Wealth Funds, Sustainable Resources, Transparency, Government Effectiveness, Bureaucratic Quality.

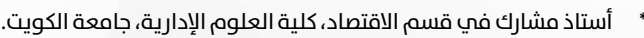
Associate Professor in the Economics Department, Administrative Sciences Faculty, Kuwait University.

Email:alshammari@cba.edu.kw 
مثّلت التحولات التي يشهدها الاقتصاد العالمي، منذ بداية القرن العشرين، تحديًا حقيقيًا للنظام المالي والاقتصادي؛ إذ أدت إلى تقلبات في حجم أوجه النشاط الاقتصادي والتبادل التجاري، ما جعله ينعكس سلبيًا على جهد الحكومات

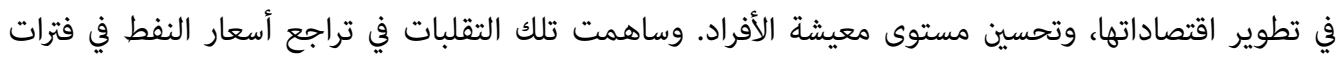

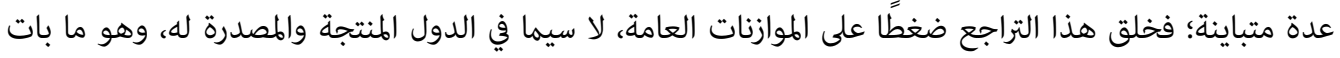
تهديدًا أيضًا لتمويل البرامج الإمائية واستمرارها، ولجهد الإصلاحات الاقتصادية فئندات في تلك البلدان. بيد أن مورد النفط

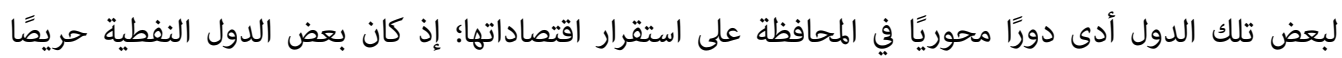

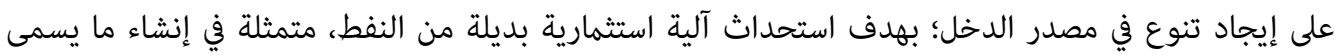
صناديق الثروة السيادية.

لقد بدأ ظهور الصناديق السيادية التقليدية في العام أوائل الخمسينيات، واعتمد على الأصول السلعية، وهو النفط

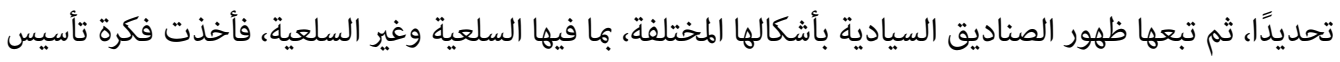
صندوق سيادي رواجًا لدى كثير من الدول. ولم يرتبط تأسيسها بوجود الرغبة لدى دول النفط في التحوط من مورد النفط الناضب فحسب، وإنما أسست الاقتصادات غير النفطية، كالصين وسنغافورة وكوريا الجنوبية وتركيا وأستراليا وتشيلي، تلك الصناديق؛ بهدف تحقيق العائد الاستثماري الملائم للحكومات، وتحقيق وفورات من موجودات الصرف

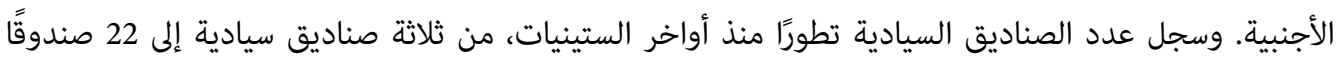

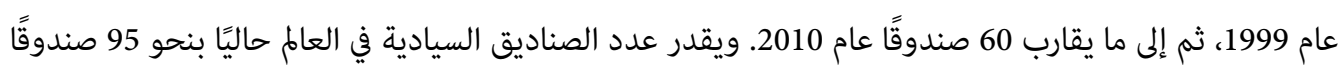

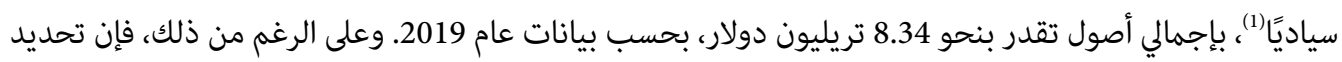

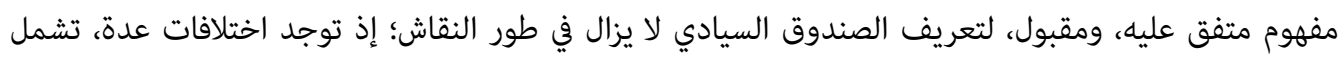

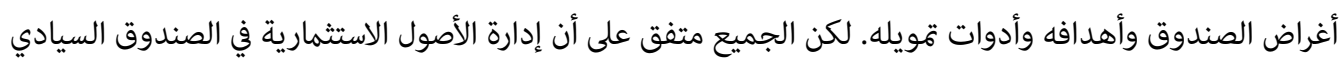

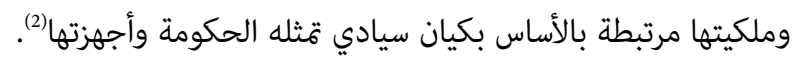

وفي ضوء ذلك، تحلل الدراسة مدى استدامة الصناديق السيادية لدول الخليج العربية، بناءً على الأهمية الاستراتيجية

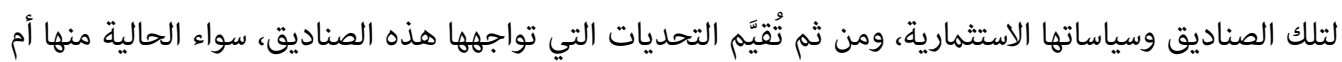

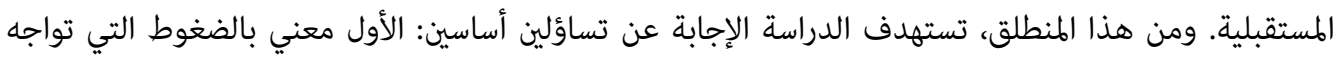

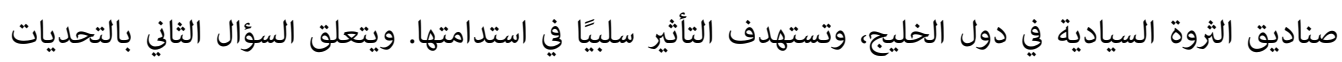
المستقبلية التي قد تواجهها هذه الصناديق. وبناءً على إجابة الدراسة عن السؤالين، ستقدم توصيات محددة. يقوم منهج الدراسة على التحليل الوصفي والتاريخي للصناديق السيادية الخليجية، عبر النظر المقارن إلى المؤشرات

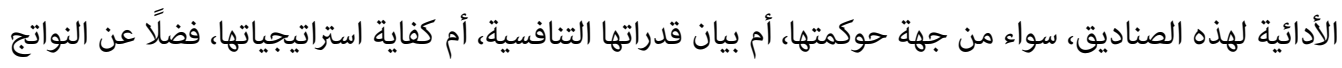

1 "Top 95 Largest Sovereign Wealth Fund Rankings by Total Assets," Sovereign Wealth Fund Institute, accessed on 1/12/2020, at: https://bit.ly/2YYudoe

2 Jeanne Amar, Christelle Lecourt \& Valerie Kinon, "Is the Emergence of New Sovereign Wealth Funds a Fashion Phenomenon?" Review of World Economics, vol. 154, no. 4 (2018), p. 853; Juergen Braunstein, "Domestic Sources of Twenty-first-century Geopolitics: Domestic Politics and Sovereign Wealth Funds in GCC Economies," New Political Economy, vol. 24, no. 2 (2019), p. 204. 
التي تمنت من تحقيقها. وتقدم الدراسة تحليلًا لسياق عمل الصناديق من منظور الاقتصاد الكلي، وتطرح تحليلًا

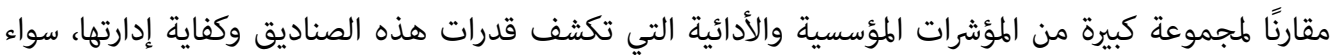

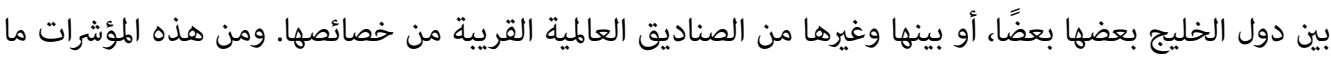

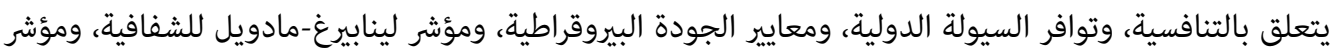
الفاعلية الحكومية، وتوازن الموازنة العامة.

تشمل الدراسة ثلاثة محاور؛ يستعرض الأول أهمية صناديق الثروة السيادية لدول الخليج، وسياساتها الاستثمارية. أما الثاني، فيحلل مدى استدامة تلك الصناديق السيادية، في حين يبين الثالث التحديات القائمة والمستقبلية لمستقبل التهاديل الصناديق السيادية الخليجية، مع تحليلها وتقييمها، إضافة إلى خاتة الدراسة وتوصياتها.

\section{أولًا: صناديق الثروة السيادية في دول الخليج العربية}

أنشأت دول الخليج العربية صناديق الثروة السيادية وسيلةً لاستخدام الوفورات المالية التي راكمتها الإيرادات النفطية؛ بغرض استثمارها، بعيدًا من تقلبات أسواق النفط. وعلى الرغم من تباين أحجام تلك الصناديق وأهدافها

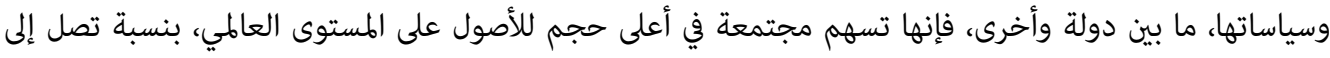

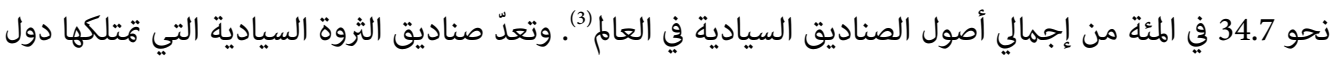
الخليج من بين أقدم الصناديق في العالم. ويوضح الجدول (1) ترتيب الصناديق الخليجية من حيث أحجام أصولها عالميًا، ويبين تواريخ إنشائها.

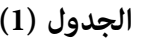

الصناديق السيادية في دول الخليج العربية

\begin{tabular}{|c|c|c|c|}
\hline الترتيب العالمي & 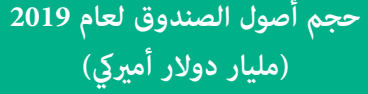 & ثاريخ التأسيس & الصندوق السيادي \\
\hline 3 & 745.00 & 1976 & هيئة الاستثمار في أبوظبي \\
\hline 6 & 527.00 & 1953 & الهيئة العامة للاستثمار الكويتية \\
\hline 7 & 512.14 & غير متوافر & صندوق الاحتياطي العام لؤسسة النقد السعودي \\
\hline 10 & 304.00 & 2005 & جهاز قطر للاستثمار \\
\hline 11 & 280.00 & 1971 & صندوق الاستثمار العام السعودي \\
\hline 12 & 239.39 & 2006 & صندوق مؤسسة دبي للاستثمار \\
\hline 14 & 229.98 & 2002 & صندوق "مبادلة" مملوك لإمارة أبوظبي \\
\hline 30 & 25.00 & 1980 & صندوق الاحتياطي العام العماني \\
\hline
\end{tabular}




\begin{tabular}{|c|c|c|c|}
\hline الترتيب العالمي & 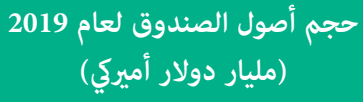 & تاريخ التأسيس & الصندوق السيادي \\
\hline 33 & 16.67 & 2006 & ممتلكات لشركة ممتلكات القابضة البحرينية \\
\hline 40 & 8.20 & 2006 & صندوق عمان الاستثماري \\
\hline 51 & 3.50 & 1982 & صندوق شركة الاستثمار الخليجي لدولة الكويت \\
\hline 65 & 0.73 & 2006 & صندوق الاحتياطي العام البحريني \\
\hline
\end{tabular}

المصدر:

"Top 95 Largest Sovereign Wealth Fund Rankings by Total Assets," Sovereign Wealth Fund Institute, accessed on 1/12/2020, at: https://bit.ly/2YYudoe

يبرز الجدول (1) التفاوت بين صناديق الثروة السيادية في دول الخليج عمرًا وحجمًا؛ فدولة الإمارات تملك أكبر الصناديق السيادية الخليجية حجمًا، وهو المملوك لهيئة الاستثمار في أبوظبي، ويحتل المركز الثالث عاميًا بعد

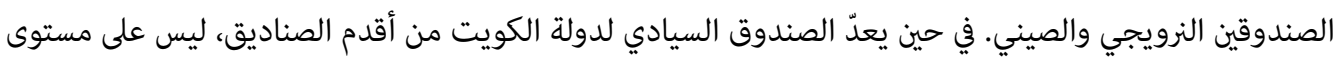
دول الخليج فحسب، بل بين دول العالم أجمع، ويحتل المركز السادس عالميًا. إضافة إلى أن من بين أقدم الصناديق

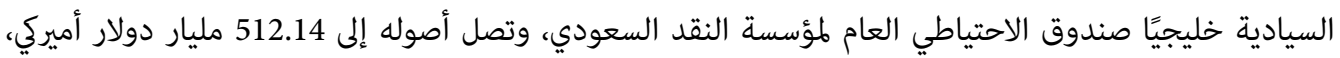
ويحتل المركز السابع عالميًا. وعلى الرغم من حداثة إنشاء الصندوق السيادي القطري الخاص، الذي أنشئ عام 2005 ضمن جهاز قطر للاستثمار، فإنه استطاع أن يحل في المركز العاشر عالميًا، بقيمة أصول مقدارها 304 مليارات دولار

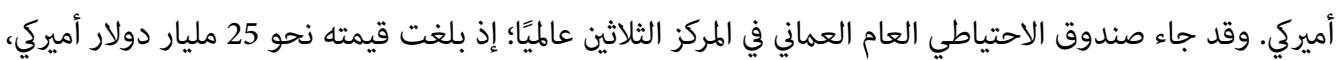
ثم صندوق الثروة السيادية "ممتلكات"، وهو التابع لشركة ممتلكات القابضة البحرينية، ويحل في المركز الثالث والثلاثين، بقيمه تقديرية تصل إلى 16.67 مليار دولار أميركي.

وبحسب كل دولة خليجية، تتصدر الإمارات، عددًا وحجمًا، الترتيب بين دول الخليج العربية، من حيث امتلاكها الصناديق السيادية، كما هو مشار إليه في الشكل (1)، فلديها ثلاثة صناديق مصنفة عالميًا على أنها صناديق سيادية، بقيمة إجمالية تبلغ 1.214 تريليون دولار أميركي، وتأتي بعدها السعودية بصناديق تبلغ قيمتها الإجمالية 792.14 تهنيا مليار دولار أميركي، ثم الكويت في المرتبة الثالثة بقيمة إجمالية قدرها 530.5 مليار دولار أميركي، ثم قطر بقيمة إجمالية بلغت 304 مليارات دولار أميركي، ثم عمان بما قيمته 33.2 مليار دولار أميركي، وأخيرًا البحرين بنحو 17.4 مليار دولار أميركي من الأصول السيادية. وبالطبع، فإن الصدمات الاقتصادية التي وقعت في بداية الألفية، ومنها الأزمة المالية العالية عام 2008، وأزمة الديون في عام 2010، وتراجع أسعار النفط، قد أثرت تأثيرًا مباشرًا في الأسواق العالمية، وفي أداء الصناديق السيادية بالتبعية (4)، فقد منيت الصناديق السيادية الخليجية بخسائر تقدر بنحو 300 مليار دولار أميركي، بحسب تقديرات معهد التمويل الدولي. 


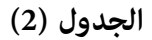

تكوين المحافظ الاستثمارية لأهم الصناديق السيادية في دول الخليج العربية

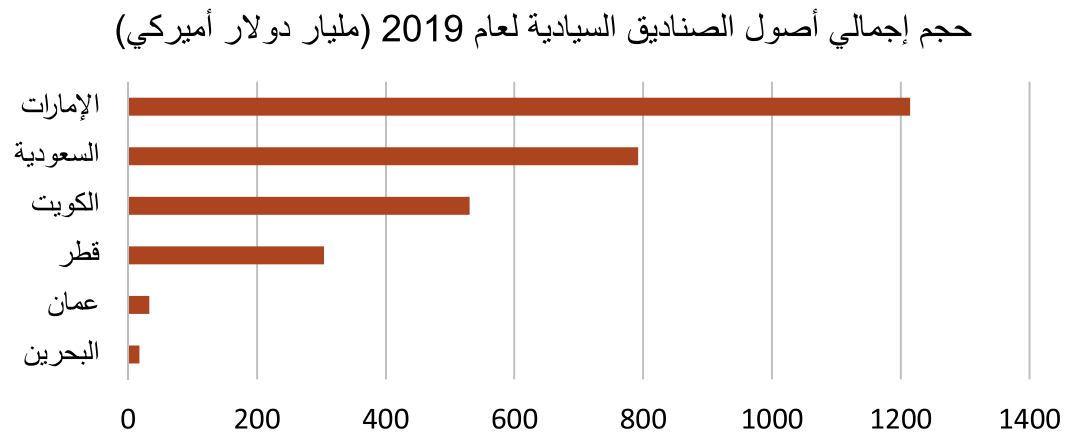

Ibid. المصدر: حساب أجراه الباحث استنادًا إلى

1. السياسات الاستثمارية للصناديق السيادية الخليجية

تركز الصناديق السيادية في الاستثمار عمومًا على ثلاث محافظ استثمارية رئيسة: أولاها محفظة الدخل الثابت، وتشمل غالبًا السيولة النقدية وأذونات الخزانة والسندات الحكومية، وثانيتها محفظة الأسهم، وتشمل أسهم المؤسسات والشركات الحكومية. وأخيرًا محفظة الاستثمارات البديلة، وتشمل استثمارات العقار، واستثمارات البنية التحتية، والاستثمارات في أسهم القطاع الخاص من مؤسسات وشركات. وبمرور الوقت يغير معظم الصناديق السيادية

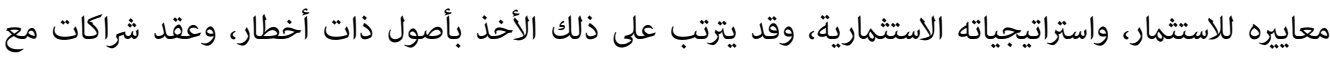

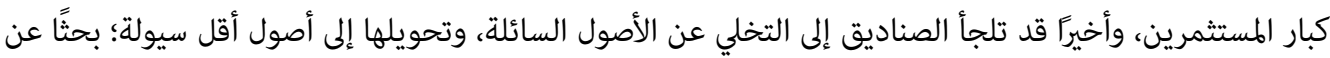

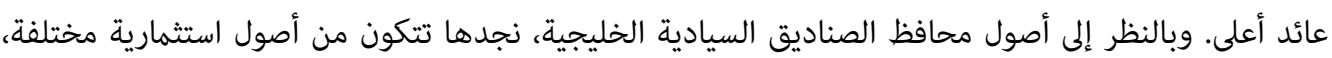
ذات عوائد متباينة. ويوضح الجدول (2) أهم الأصول التي تستثمرها أهم الصناديق السيادية في دول الخليج،

$$
\text { بحسب البيانات المتوافرة. }
$$

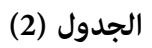

تكوين المحافظ الاستثمارية لأهم الصناديق السيادية في دول الخليج العربية

\begin{tabular}{|c|c|c|c|}
\hline محفظة الاستثمارات & محفظة الأسهم & محفظة الدخل & الصندوق السيادي \\
\hline 5 & 55 & 40 & صندوق الاحتياطي العام لمؤسسة النقد السعودي \\
\hline 9 & 58 & 33 & الهيئة العامة للاستثمار الكويتية \\
\hline 33 & 33 & 33 & صندوق الاستثمار العام السعودي \\
\hline
\end{tabular}




\begin{tabular}{|c|c|c|c|}
\hline محفظة الاستثمارات & العامة (في المئة) الأسهم & الثابت (في المئة) الدخل & الصندوق السيادي \\
\hline 22 & 52 & 26 & صندوق جهاز الاستثمار في أبوظبي \\
\hline 45 & 30 & 25 & صندوق الاحتياطي العام العماني \\
\hline 20 & 60 & 20 & جهاز قطر للاستثمار \\
\hline 90 & 5 & 5 & صندوق عمان الاستثماري \\
\hline 46 & 54 & 0 & صندوق مؤسسة دبي للاستثمار \\
\hline 75 & 25 & 0 & صندوق "مبادلة" مملوك لإمارة أبوظبي \\
\hline 85 & 15 & 0 & ممتلكات لشركة ممتلكات القابضة البحرينية \\
\hline
\end{tabular}

Ibid. : المصدر

يُلاحظ من الجدول (2) أن معظم الصناديق السيادية الخليجية قد ركزت استثماراتها السيادية في محفظة الاستثمارات البديلة؛ إذ تتميز بمتوسط للعائد السنوي معتدل، يُقدر بنحو 8 في المئة في القطاع العقاري، ونحو 10 في المئة في قطاع البنية التحتية، بينما نجد أقل تلك الاستثمارات في محفظة الدخل الثابت، وهي تدر أقل العوائد، مقارنة بالمحافظ

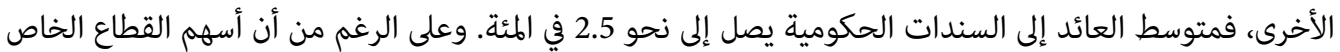
تدر أعلى عوائد، وسطيًا نحو 16 في المئة، فإنها تعتبر محافظ ذات خطورة مرتفعة، مقارنة بالهحافظ الاستثمارية

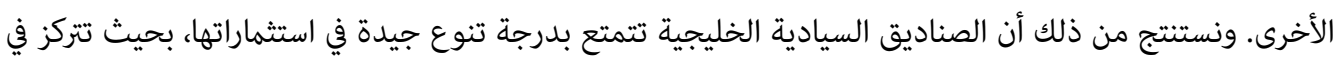
قطاعات ذات عوائد معتدلة، وتتصف بدرجة أخطار معتدلة، وتتحاشى الدخول في أصول مضاربية(5).

\section{2. التوزيع القطاعي والجغرافي لاستثمارات صناديق الثروة السيادية الخليجية}

عند الحديث عن التوزيع القطاعي والجغرافي لاستثمارات صناديق الثروة السيادية الخليجية، فإن تحديد التوزيع الجغرافي لتدفقات هذه الصناديق يعد من أهم استراتيجياتها الاستثمارية؛ إذ إنها منكشفة لفرص الاستثمار في

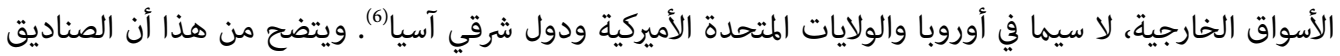
السيادية لدولة الإمارات تستثمر بوزن أكبر في أسواق المال العالية، وبنسبة أقل في السندات الحكومية والبنية التحتية والعقارات. فعلى سبيل المثال، هناك استثمارات لجهاز أبوظبي للاستثمار في مشروعات التطوير العقاري ومراكز التسوق في الولايات المتحدة الأميركية. أما مؤسسة دبي للاستثمار، فتشمل استثمارات في أكثر القطاعات تنوعًا، كقطاع التمويل والاستثمار والنقل والطاقة والصناعة والعقارات والبناء والضيافة والترفيه وقطاع التجزئة. أما ما يخص الهيئة العامة للاستثمار الكويتية، فإن استثمارات صندوقها السيادي تتركز في سوق المال الأميركية، وفي اليابان والصين

5 Bahgat Gawdat, "Sovereign Wealth Funds in the Gulf: An Assessment," Kuwait Programme on Development, Governance and Globalization in the Gulf States (16) (London: The London School of Economics and Political Science, 2011); Rios-Morales Ruth, Mohamed A. Ramady \& Louis Brennan, "GCC Sovereign Wealth Funds: Challenges, Opportunities, and Issues Arising from their Growing Presence on the Global Landscape," in: Mohamed A. Ramady (ed.), The GCC Economies Stepping Up to Future Challenges (New York: Springer, 2012), p. 5.

6 Mehmet Asutay, "GCC Sovereign Wealth Funds and Their Role in the European and American Markets," Equilibri, vol. 12, no. 3 (2008), p. 6. 
وبعض الدول الأوروبية، لا سيما في قطاعات الفندقة والصناعة والتأمين والخدمات المالية والاستثمارات العقارية. أما الصندوق السيادي الخاص بمؤسسة النقد العربي السعودي، فُيعرف ارتباطه باستثمارات محدودة الأخطار، واعتمدت

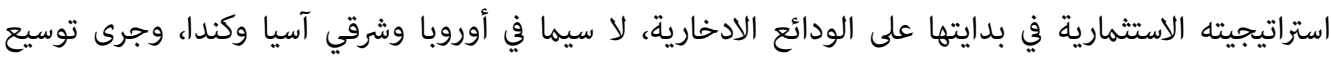

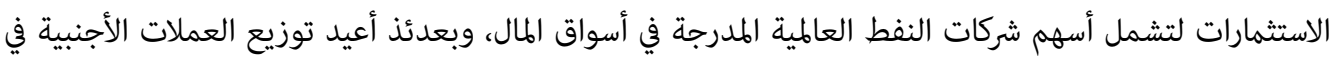
المحفظة الاستثمارية. أما بالنسبة إلى صندوق الاستثمار العام السعودي، فيركز على الاستثمارات في السوق المحلية والدولية، لا سيما قطاع البترول والصناعات الأساسية والتعدين، والقطاع المالي.

تجدر الإشارة إلى توجه بعض الصناديق السيادية الخليجية نحو الاستثمار في قطاعات الطاقة النظيفة؛ فالصندوق الخاص في جهاز أبوظبي للاستثمار لديه استثمارات في شركة Greenko في الهند، وهي شركة مهتمة بإنشاء أصول متكاملة للطاقة المتجددة، كذلك صندوق الاستثمارات العامة السعودي الذي اتجه جزء من استثماراته نحو تشغيل مشروعات الطاقة المتجددة ACWA، وتصنيع السيارات الكهربائية Tesla Lucid. أما شركة "مبادلة للاستثمار"، فيلاحظ أن لديها استثمارات في قطاع البنية التحتية للطاقة المتجددة.

إن تأسيس صناديق الثروة السيادية يعتمد على أسس قانونية مختلفة محددة، مرتبطة بإنشائها، وإدارة أوجه نشاطها (أي: القانون التأسيسي والقانون المالي والدستور والقوانين واللوائح الأخرى)، وهو ما يجعل إمكانية التغيير في استراتيجيتها الاستثمارية محدودة، إلى حدٍ ما، وهذا ما توضحه نوعية المحافظ الاستثمارية لهذه الصناديق المتسمة بالتنوع، وتعتمد الاستثمار الاستراتيجي طويل الأمد. من هنا نفهم دوافع تركيز الاستراتيجية الاستثمارية مائه

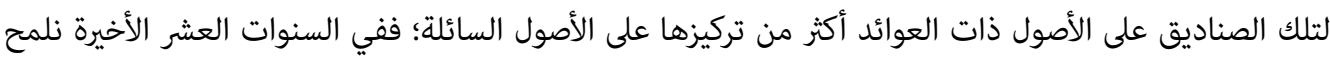
اتجاهًا واضًا للصناديق الخليجية نحو البحث عن أعلى العوائد، من خلال زيادة المخصصات للأسهم، مقابل انخفاض مخصصات السندات.

\section{ثانيًا: استدامة صناديق الثروة السيادية في دول الخليج العربية}

تتباين أهداف إنشاء الصناديق السيادية الخليجية ومسوغاته، وتتنوع بحسب كل صندوق على حِدة. ونجد أن أحد أهم محاورها، وهو المرتبط بطبيعة اقتصاديات دول المجلس، هو حماية الاقتصاد المحلي من تقلبات عوائد

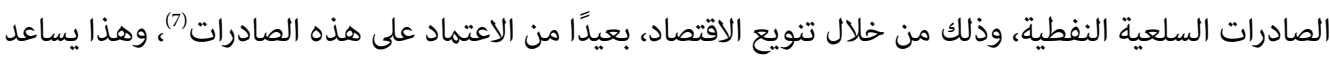

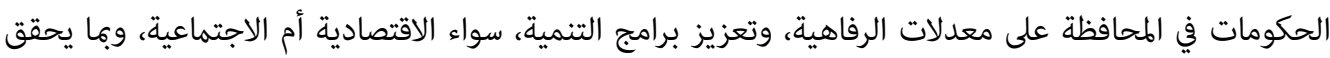
الأهداف الاستراتيجية للنمو المستدام، والاستقرار السياسي والاقتصادي في البلاد.

ويعتبر مورد النفط واحتياطي الصرف أهم مصدرين لتمويل الصناديق السيادية في العام؛ لذلك نجد أن الدول النفطية، ومن بينها دول الخليج، تول صناديقها السيادية من خلال عائدات النفط، بينما نجد الدول الآسيوية وأستراليا تول صناديقها من خلال احتياطي الصرف الأجنبي المتحصل من عوائد صادراتها السلعية وغير السلعية (8).

7 7 ماجد المنيف، "صناديق الثروة السيادية ودورها في إدارة الفوائض النفطية"، مجلة النفط والتعاون الدولي، مج 35، العدد 129 (2009)، م 7. 8 
وكما هو مبين في الشكل (2) فإن النفط، بما هو مصدر أساس ورئيس لتمويل استثمارات الصندوق، يعرّض التدفقات النقدية لانكشافٍ عال، عند وجود أي تقلّب في أسواق النفط.

(2) الشكل

مصادر تمويل أهم صناديق الثروة السيادية في العالم

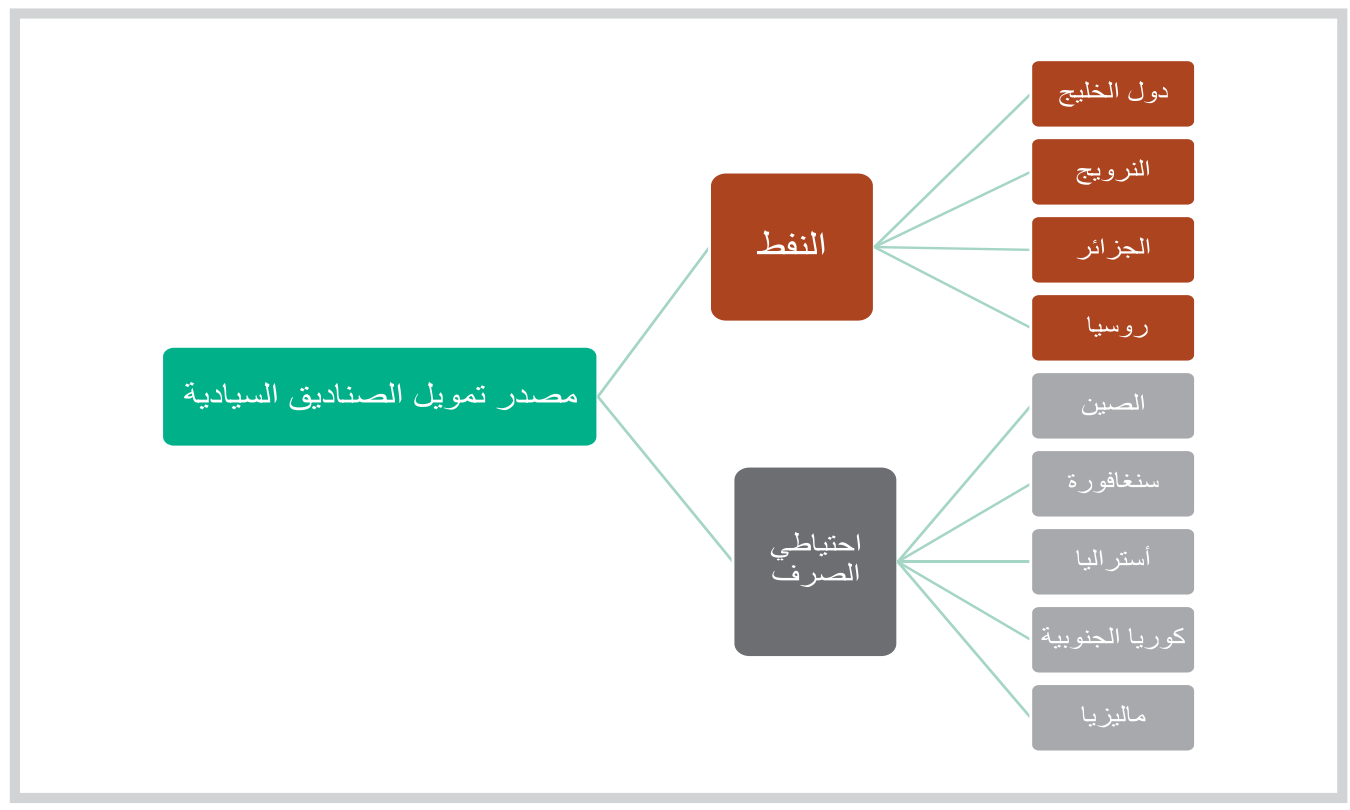

Ibid. المصدر

(3) الشكل (3) من (3)

مساهمة الصندوق السيادي من الناتج المحلي الإجمالي (3019)

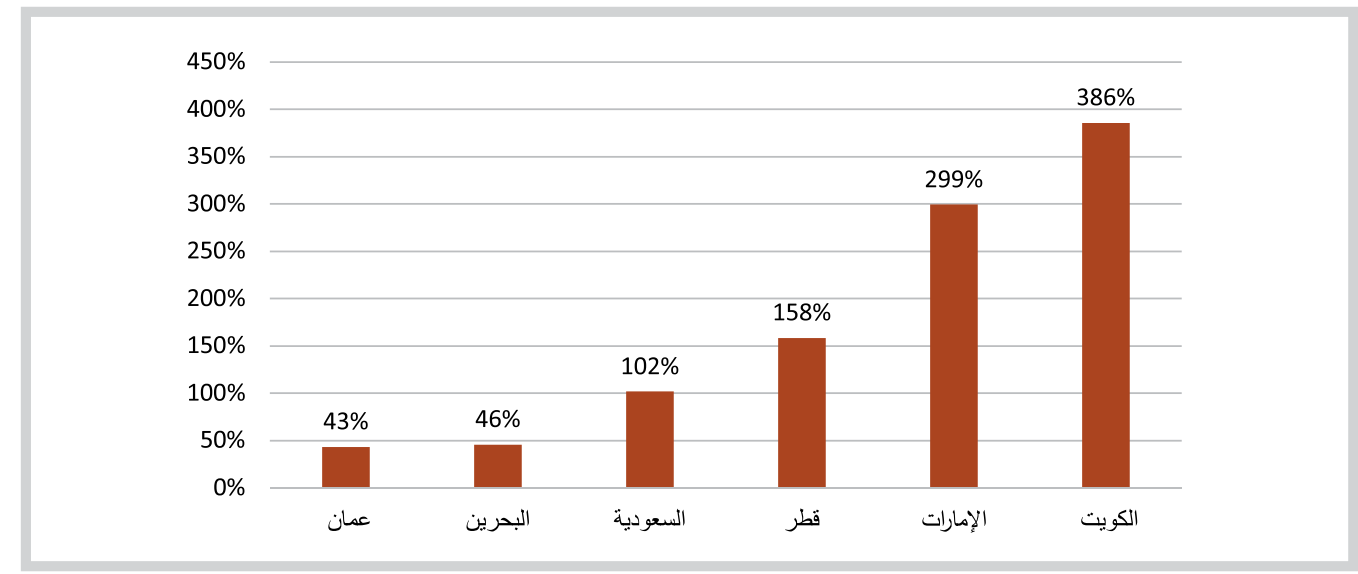

المصدر: حساب أجراه الباحث استنادًا إلى:

World Bank, World Development Indicators (WDI) 2020, Washington DC, accessed on 20/12/2020, at: https://bit.ly/39Yqzku; "Top 95 Largest Sovereign Wealth Fund Rankings by Total Assets." 
من هذا المنطلق، ونظرًا إلى المساهمة العالية للقطاع النفطي في الاقتصاد الخليجي، وما ترتب عليه من تعزيز استثمارات صناديقها السيادية، فإن دول الخليج تسجل مساهمة مرتفعة لنصيب حجم صناديق الثروة السيادية، نسبة إلى الناتج المحلي الإجمالي عام 2019؛ إذ يصل مجموع أصول الصناديق السيادية الخليجية إلى نحو 385.6 في

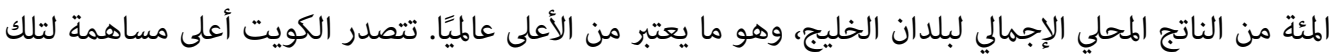

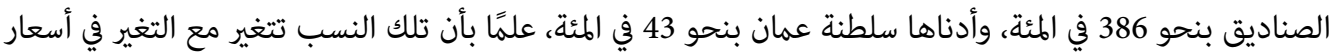
النفط، وما يصاحبه من تراجع في الإيرادات النفطية، من جانب، والناتج المحلي الإجمالي، من جانب آخر.

يُظهر الشكل (4) بجلاء أن مساهمة العوائد النفطية من الناتج المحلي الإجمالي لدول الخليج ترتبط أساسًا بحركة

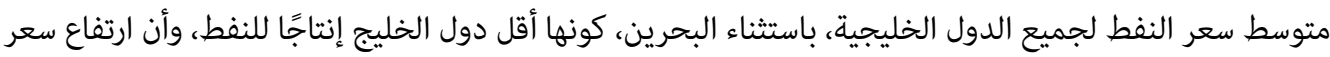

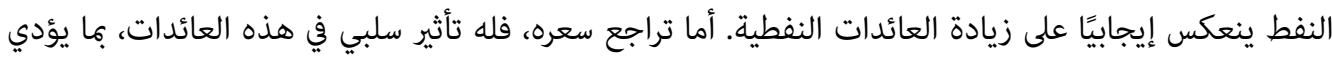
إلى خلق صدمات اقتصادية، مع تقلب العوائد الحكومية ومعدلات النمو في الناتج المحلي الإجمالي. لقد تراكمت

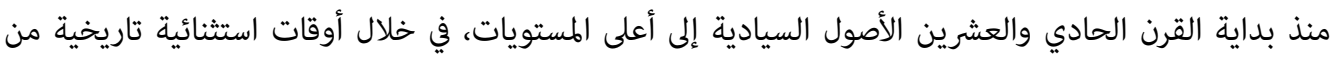

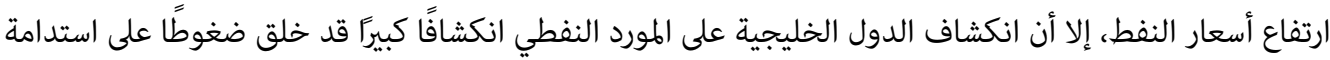
صناديق الثروة السيادية، لا سيما في الأوقات التي تنخفض فيها أسعار النفط.

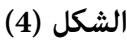

مساهمة العوائد النفظية من الناتج المحلي الإجمالي

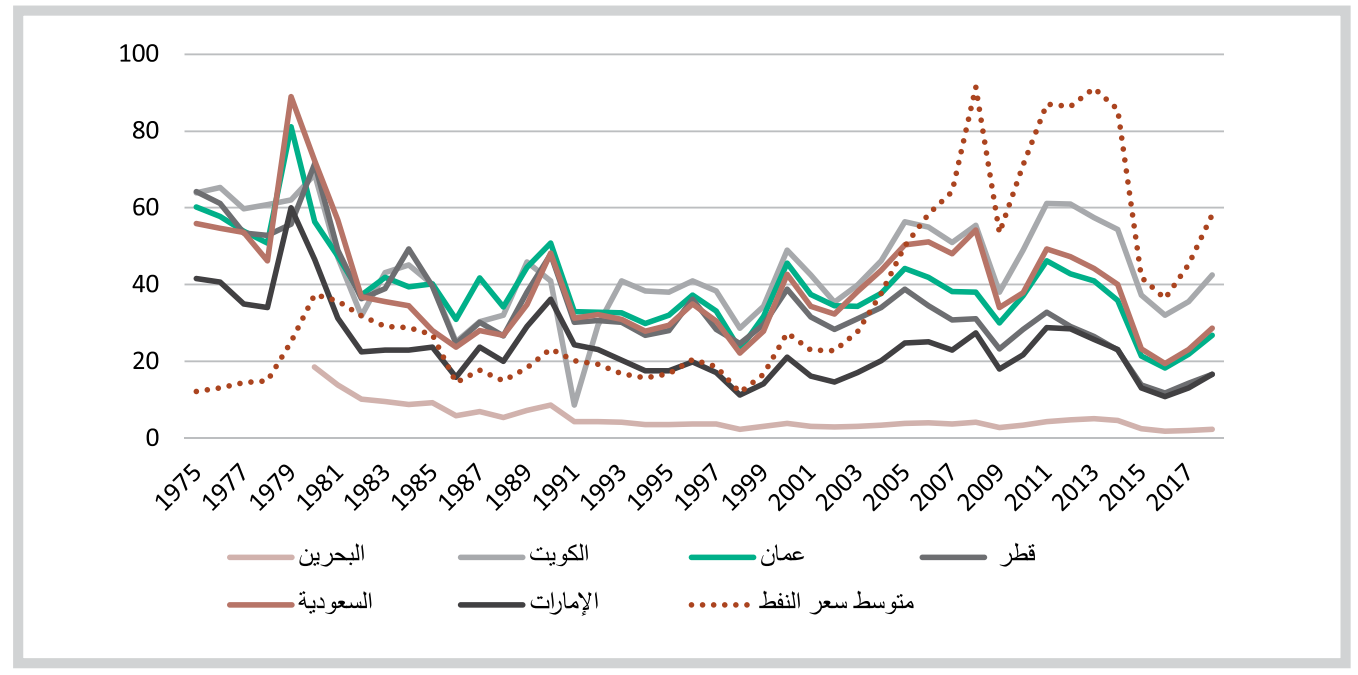

Ibid. : المصدر

1. التقلبات في معدل النمو الاقتصادي

في هذا السياق طرأت تشوهات على اقتصادات دول الخليج؛ من جراء تقلبات العوائد النفطية، وظهور تقلبات دورية في معدلات فو الناتج المحلي الإجمالي. ويبين الشكل (5) تقلبات معدلات فو الناتج المحلي الإجمالي الحقيقي 
لدول الخليج، مقاسًا بقيمة الانحراف المعياري Standard Deviation ونجدها مرتفعة في خلال الفترة 1970-2019؛ إذ سجلت السعودية أعلى درجة انحراف لمعدل نمو الناتج المحلي الإجمالي الحقيقي، بعد لبنان، بنحو 11.92 نقطة،

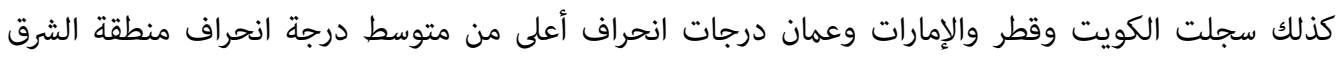
الأوسط وشمالي أفريقيا. وهذه النتيجة، في حد ذاتها، كفيلة بفهم درجة الانكشاف العالية لاقتصادات دول دول الخليج على تقلبات أسعار النفط، وكيف أنها تؤثر بالتبعية في تنفيذ أي سياسة، أو قرار، تُعنى بالإصلاحات الاقتصادية والمالية، سواء بتأجيلها أو تعديلها أو إلغائها (9).

الشكل (5)

التقلبات في معدل نهو الناتج المحلي الإجمالي الحقيقي (1970-2019)

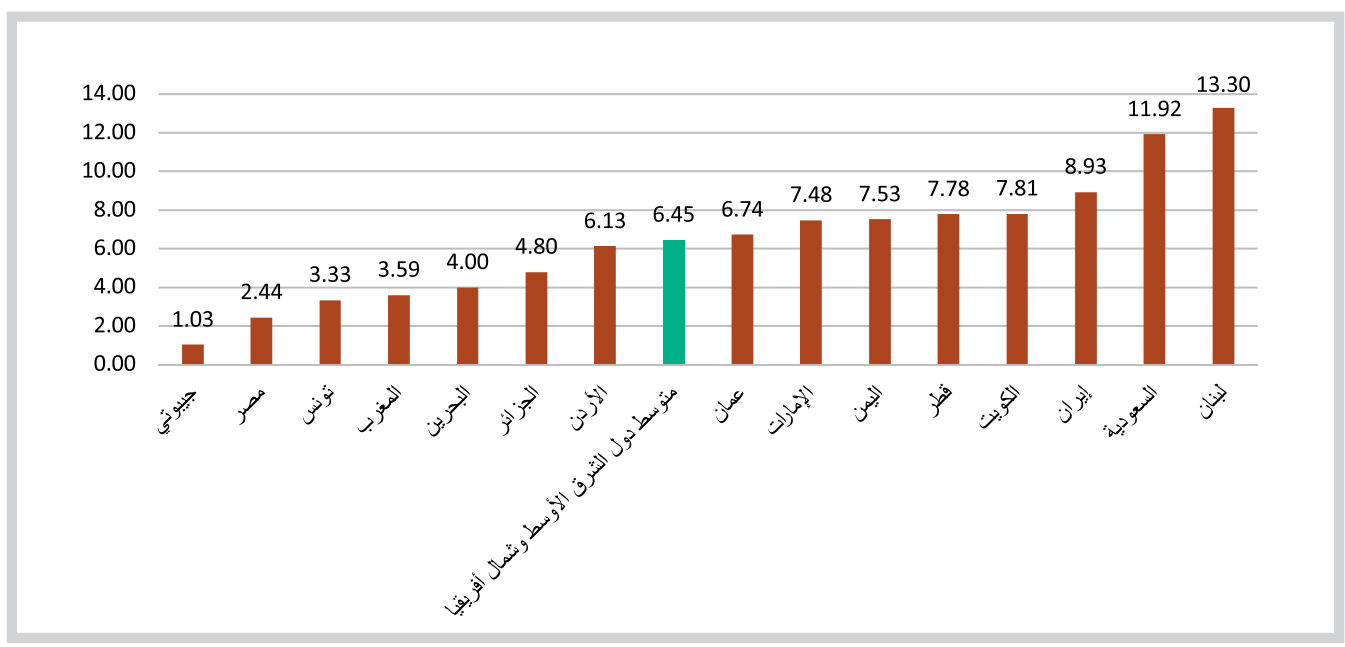

المصدر: حساب أجراه الباحث استنادًا إلى بيانات معدلات النمو التي أصدرها البنك الدولي.

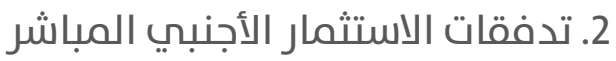

إن نجاح الصناديق السيادية لا يتمثل، فحسب، في تحقيق العوائد المالية، وتراكم أصوله الاستثمارية، بوصفها

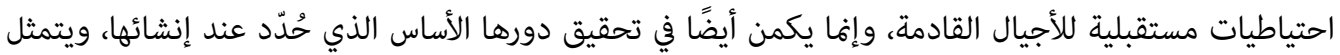
في إفاء اقتصادات الدول المالكة لها وتنويعها. لذلك، فإن عدم ممارسة هذا الدور يعيق تحقق هدف الصناديق السيادية في حماية الاقتصاد المحلي من تقلبات العوائد النفطية، إضافة إلى أن تنويع أوجه نشاط الاقتصاد المحلي واستدامتها، بعيدًا من النفط، وتحجيم الانكشاف على عجز الموازنة العامة، وتحقيق الاستقرار الاقتصادي بالتوسع في أوجه النشاط غير النفطية، ما هي إلا متطلبات تعكس مدى نجاح تلك الصناديق السيادية (10.).

9 سفيان بو زيد، "دور صناديق الثروة السيادية في ترشيد الإيرادات النفطية"، مجلة البحوث السياسية والإدارية، مج 3، العدد 4 (2016)، ص 69. 10 والاستراتيجية، 2019)، صور صناديق الثوة 7. 
Foreign Direct Investment- Net inflow ويبين تحليل التطور التاريخي لصافي تدفقات الاستثمار الأجنبي المباشر في دول الخليج، كما في الشكل (6) المستويات المتدنية لحجم تلك التدفقات، خلال فترة الثمانينيات والتسعينيات من القرن المنصرم، لجميع دول الخليج. بيد أن تلك الدول أدركت أهمية استثمارات المستثمر الأجنبي محليًا في بداية الألفية، من خلال تقليل القيود، وتبسيط الإجراءات الكفيلة باستقطاب المستثمرين الأجانب؛ من أجل تنويع الاقتصاد

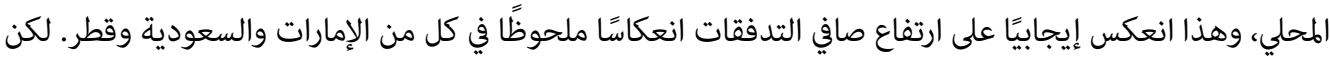
سرعان ما تراجعت تلك التدفقات بعد الأزمة المالية العالهية، عام 2008، إلى مستويات متدنية. والتصور العام لحركة تلك التدفقات في دول المجلس لا يعكس إطلاقًا اهتمام الحكومات بتنويع اقتصاداتها بعيدًا من المورد النفطي، على لى الرغم من تراكم الأصول السيادية التي قد تسهم في تنويع الناتج المحلي، وفي تطوير أوجه نشاط اقتصادي أخرى.

الشكل (6)

الاستثمار الأجنبي المباشر- صافي التدفقات (مليار دولار أميركي)

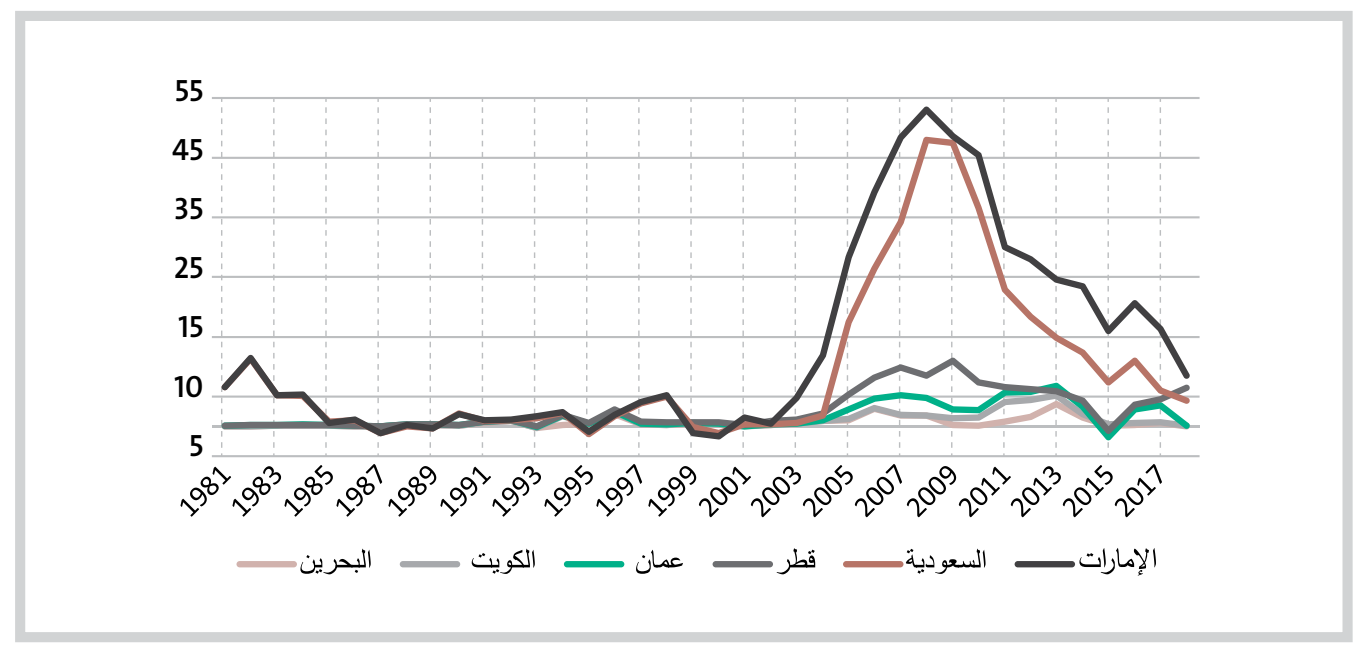

المصدر: World Bank, World Development Indicators (WDI) 2020

\section{3. قياس درجة البيروقراطية}

إن إحدى الطرق للتعرف إلى أداء المؤسسات في الدول تكون من خلال قياس درجة البيروقراطية Bureaucracy Quality، أو ما يسمى بسيادة الإجراءات الإدارية والقانونية، فلإنشاء الصناديق السيادية أهداف اقتصادية واستثمارية وأيضًا سياسية يسعى لتحقيقها، في حين أن تفشّي البيروقراطية، ومن ثم تراجع الاستثمارات الأجنبية المباشرة التي

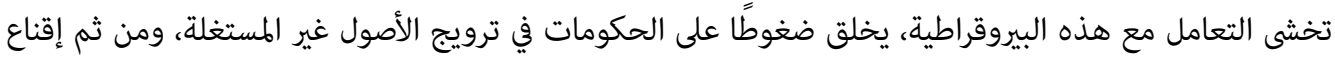

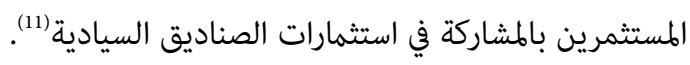

11 Robert Kimmitt, "Public Footprints in Private Markets: Sovereign Wealth Funds and the World Economy," Foreign Affairs, vol. 87, no. 1 (2008), p. 128. 
إن إزالة التعقيدات البيروقراطية والإدارية، وتحسين بيئة أداء الأعمال في الاقتصاد المحلي، من شأنهما تعزيز التعامل مع التنظيم المطلوب في صناديق الثروة السيادية، ويوضح الشكل (7) أن متوسط معيار جودة الإجراءات البيروقراطية

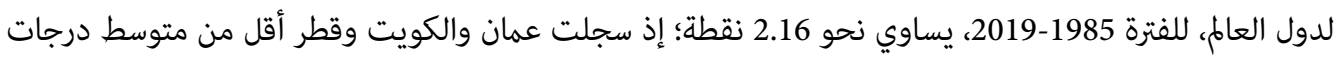

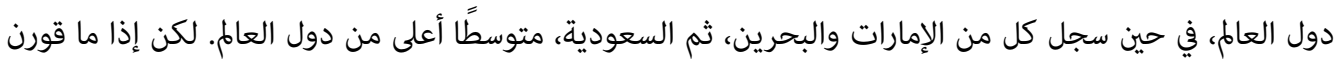

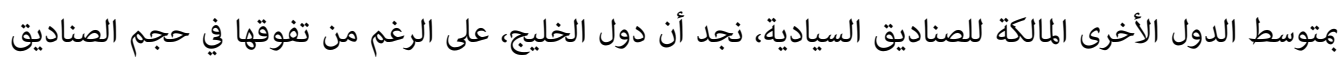

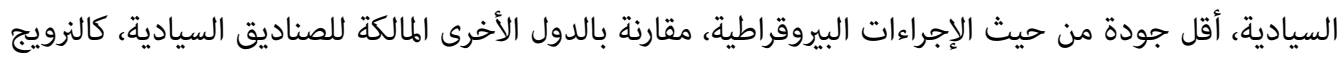

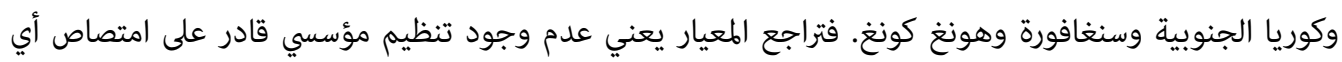

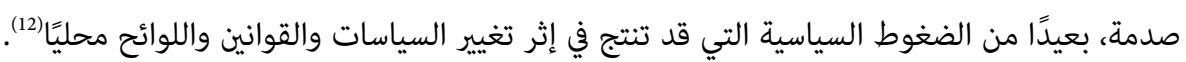

(7) الشكل

معيار الجودة للبيروقراطية

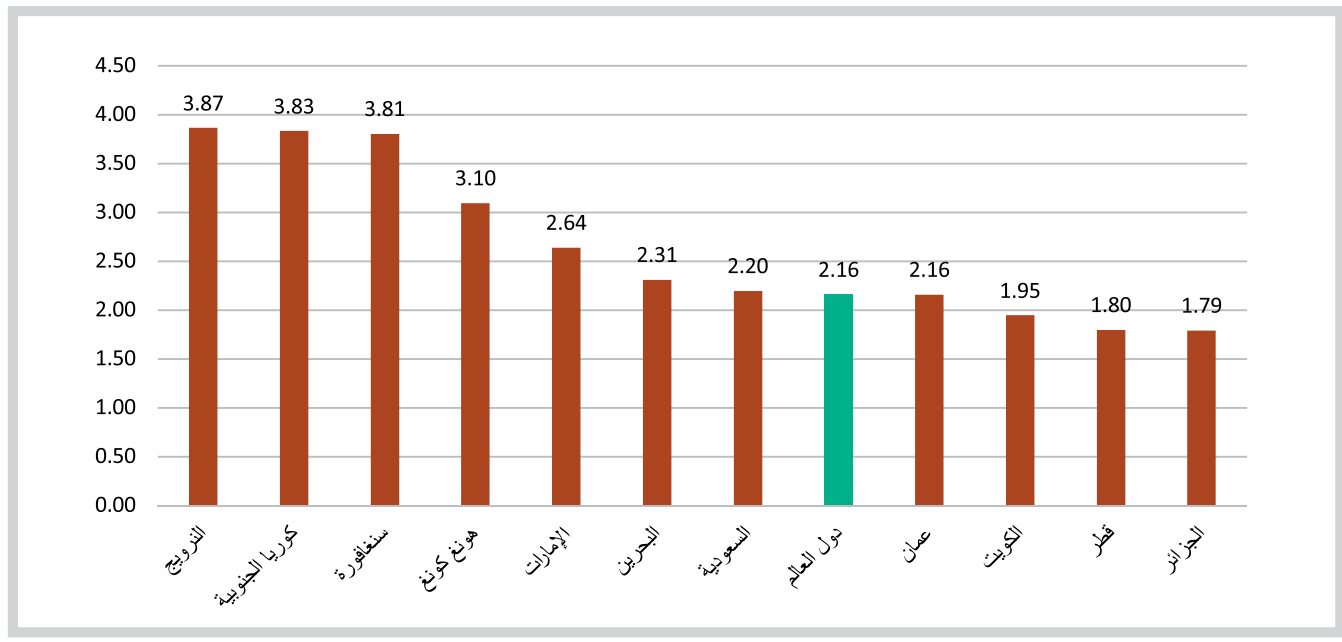

المصدر:

Political Risk Services (PRS) Group, "The International Country Risk Guide (ICRG)," accessed on 25/11/2020, at: https://bit.ly/3rAi2Kk

والخلاصة هي أن انكشاف الصناديق السيادية الخليجية، إلى درجة كبيرة، على العائدات النفطية يحيد بها عن

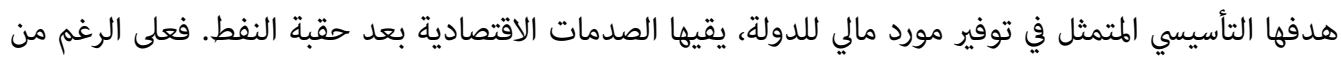

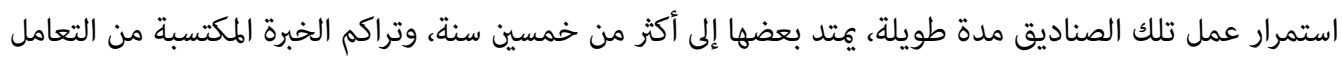

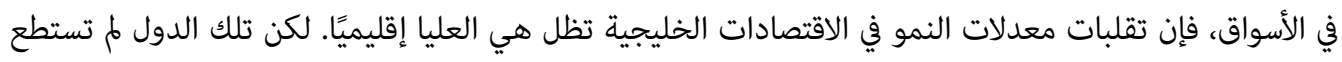

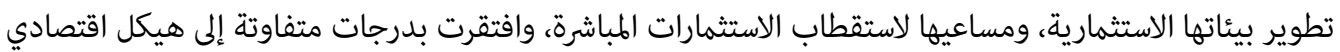
محلي ملائم، يؤهلها إلى مرحلة ما بعد النفط.

12 Jocelyn Grira, Chiraz Labidi \& Wael Rouatbi, "Does Political Risk Matter for Sovereign Wealth Funds? International Evidence," International Review of Financial Analysis (2018), accessed on 25/11/2020, at: https://bit.ly/3rtd02O; Sara Bazoobandi \& Alexander Rhiannon, "GCC Oil Wealth: The Power and the People," in: Sara Bazoobandi (ed.), The New Regional Order in the Middle East, International Political Economy Series (Cham, Switzerland: Palgrave Macmillan, 2020), accessed on 25/11/2020, at: https://bit.ly/3p31id5 


\section{ثالثًا: التحديات القائمة والمستقبلية لمستقبل ثروة دول المبات الخليج العربية الممثلة في الصناديق السيادية}

بالنظر إلى طبيعة الصناديق السيادية في دول الخليج العربية، يمكن تبين ميزات مشتركة في ما بينها، على الرغم من اختلاف أحجام أصولها. أول هذه السمات أن الحكومات، بوصفها مالكة لهذه الصناديق، لديها الميزة الكبرى. لكن تمويل الصناديق يعتمد بدرجة عالية على العوائد النفطية. ثمة كذلك سمات إدارية بعضها سلبي، منها أن درجة الإفصاح عن عمليات الصناديق، وأوجه نشاطها الاستثماري، متدنية جدًا، إذا ما قورنت بالصناديق السيادية الأخرى في الصين والنرويج(13. وعلى الرغم مما تمتاز به الصناديق السيادية في العالم، فإن ثة تحديات مستقبلية تواجهها، بما فيها الصناديق السيادية الخليجية. يظهر الشكل (8) خمسة من التحديات الأساسية؛ أولها أن مصدر التمويل الأكبر لأوجه نشاط

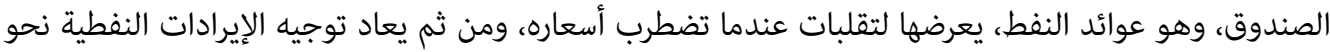

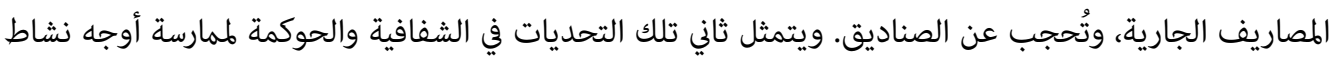

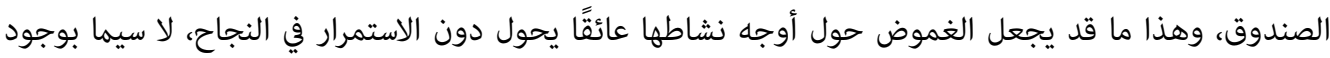
ضغوط عالهية من المنظمات الدولية والدول المتقدمة، دفعًا نحو مزيد من الشفافية لأعمال الصناديق، والإفصاح

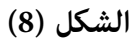

التحديات المستقبلية لصناديق الثروة السيادية في دول الخليج العربية

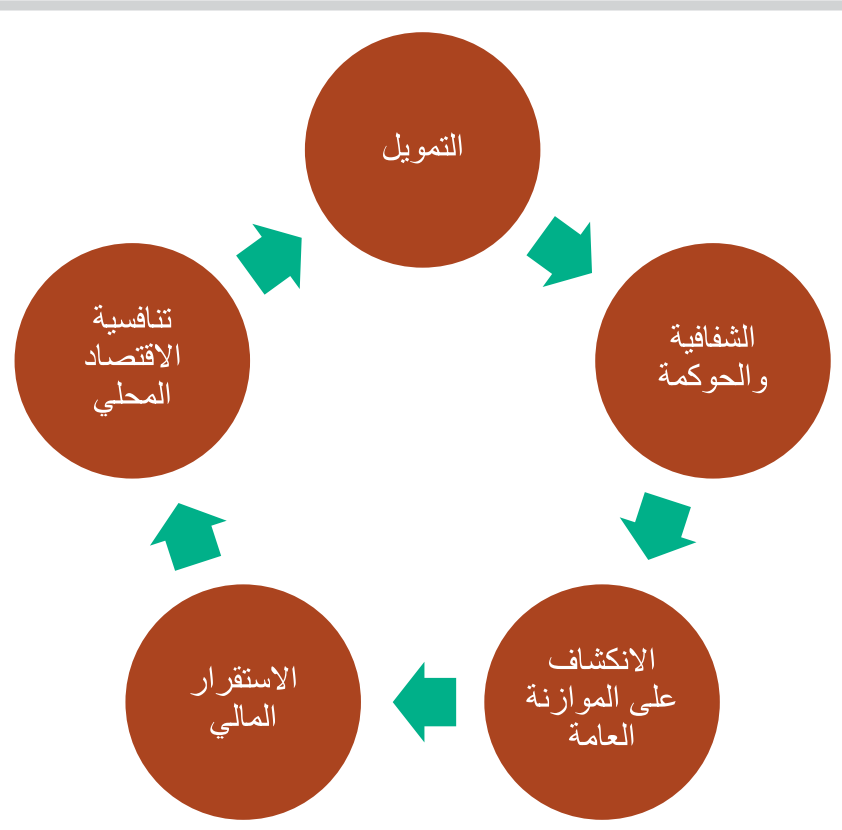

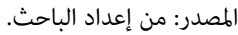


عن ماهية عملها(14) يشمل التحدي الثالث درجة انكشاف عوائد الصندوق على تمويل العجز في الموازنة العامة، بما يترتب عليه تراجع في احتياطيات الصناديق واستثماراتها، في حالة تسييل الأصول الاستثمارية المرتبطة بأوجه نشاط الصناديق. أما التحدي الرابع فيتعلق بِستوى الاستقرار المالي في دول الخليج، وبمدى توافر السيولة الكافية في الاقتصاد، وأخيرً التحدي المتعلق بقدرة دول الخليج على تطوير تنافسية اقتصاداتها، بما يرفع من إسهام القطاعات المختلفة في الاقتصاد والتنمية.

\section{1. تمويل الصناديق السيادية الخليجية}

تُعدّ طريقة تمويل التدفق المالي للصناديق في دول الخليج من أهم الوسائل لتحسين عملية إدارة الصندوق، وتجري

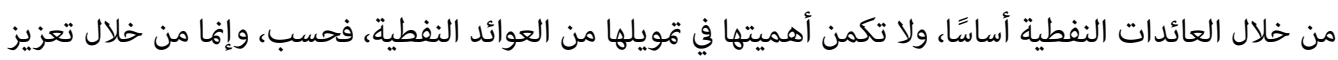

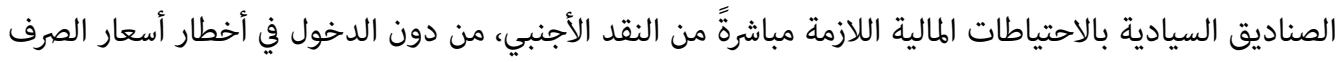
والتحويل بين العملات.

فالتقلبات في أسواق النفط تؤثر في حجم استثمار دول الخليج وأفاطه؛ إذ يضع التراجع في أسعار النفط، على الأمد

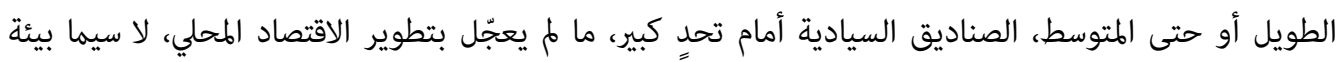

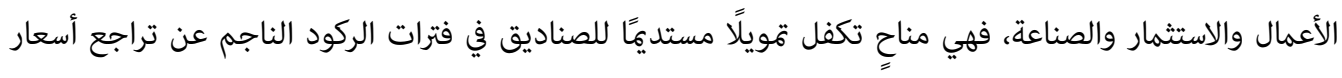
النفط. إن الاستفادة من الأوضاع المواتية، بوجود تكلفة منخفضه لإنتاج النفط، وأسعار مرتفعة عند بيعه، تخلق فرصًا حقيقية لتطوير الصناعات، وتأخير الاستثمار في تلك الصناعات قد يعني رفع التكلفة في الأمدين المتوسط والطويل. لكن تتمثل الميزة في أن العوائد من الصناعات تتحقق عادة في الأمد الطويل.

إن مستقبل تمويل الصناديق السيادية مرهون بتطوير اقتصادات دول المجلس وتنويعها، بما يكفل تدفقًا ماليًا لتمويل الصناديق في المستقبل، في حال تراجع الفوائض المالية، أو عدم كفايتها لتمويل الموازنة العامة للدولة.

\section{2. الشفافية والحوكمة}

يقيس مؤشر لينابيرغ-مادويل لشفافية الصناديق السيادية Linaburg-Maduell Transparency Index لمعهد صندوق الثروة السيادية، مدى الشفافية في عمل الصناديق السيادية وتعاملاتها المالية. ويراوح المؤشر بين رقم (1) وهو

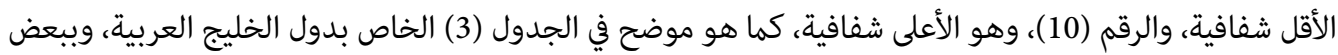

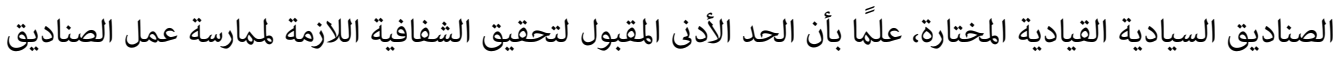
السيادية هو الحصول على ثاني نقاط في المؤشر، كما يشير إليه معهد صندوق الثروة السيادية. ويقيس المؤشر قياسًا أدق المبادئ المتعلقة بإنشاء الصندوق، ومصدر التمويل، والهيكل التنظيمي للكية الحكومة بالصندوق، كذلك يقيس إسل المؤشر شفافية التقارير السنوية لأوجه نشاط الصندوق، ومدى وضوح إدارة الاستراتيجية الاستثمارية للصندوق. 
(3) الجدول

مؤشر لينابيرغ-مادويل لشفافية الصناديق السيادية لعام 2019

\begin{tabular}{|c|c|}
\hline النقاط المتحصل عليها في مؤشر لينابيرغ-مادويل للشفافية & الصندوق السيادي \\
\hline 10 & صندوق التقاعد النرويجي \\
\hline 10 & 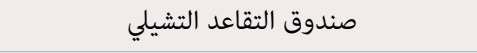 \\
\hline 10 & صندوق المستقبل الأسترالي \\
\hline 10 & صندوق "مبادلة" (مملوك لإمارة أبوظبي) \\
\hline 10 & ممتلكات لشركة ممتلكات القابضة البحرينية \\
\hline 8 & صندوق تاسك القابضة السيادي في هونغ كونغ \\
\hline 7 & صندوق الاستثمار العام السعودي \\
\hline 6 & الهيئة العامة للاستثمار الكويتية \\
\hline 6 & صندوق جهاز الاستثمار في أبوظبي \\
\hline 5 & جهاز قطر للاستثمار \\
\hline 5 & صندوق مؤسسة دبي للاستثمار \\
\hline 4 & صندوق الاحتياطي العام العماني \\
\hline 4 & صندوق عمان الاستثماري \\
\hline 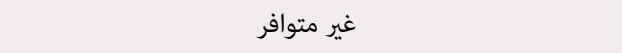 & صندوق الاحتياطي العام كؤسسة النقد السعودي \\
\hline
\end{tabular}

المصدر: "Top 95 Largest Sovereign Wealth Fund Rankings by Total Assets".

يلاحَظ من الجدول (3) أن الصناديق السيادية التابعة لدول الخليج قد حصلت على أقل من نقاط الحد الأدنى المقبول، وهو ثماني نقاط في مؤشر لينابيرغ-مادويل للشفافية، باستثناء صندوق "مبادلة" المملوك لإمارة أبوظبي، وصندوق "ممتلكات البحريني. وإذا ما قورنت الصناديق الخليجية الأخرى بالصناديق السيادية العالمية المماثلة لها في الحجم، نجد أن الصناديق الخليجية جاءت أقل من الشفافية المرصودة في عمل الصناديق السيادية الأخرى التي تتميز بالشفافية والحوكمة العالية، كالصناديق السيادية في النرويج وتشيلي وأستراليا(15.) إن هذا في حد ذاته يعزز الحاجة إلى مزيد من الشفافية في عمل الصناديق الخليجية؛ إذ إن غياب الشفافية عنها صار سمة ملازمة، ويضعها في مرتبة متأخرة عن الصناديق السيادية الأخرى ذات الحجم والتوجهات الاستثمارية نفسيهما. تجدر الإشارة إلى أن الأوضاع عامةً في أي دولة، من حيث مستوى الحوكمة مناخها والشفافية ومتانة التشريعات، تنعكس بالقدر نفسه على مستوى شفافية عمل صناديقها السيادية، والتعامل مع استثمار أصولها (16. يبين الشكل (9)، على سبيل المثال، تراجع الصناديق الخليجية في معيار متانة التشريعات، منذ بداية الألفية الثالثة. وهو الأمر الذي يعكس التعقيدات في المجال التشريعي، وفي الإجراءات الخاصة بعمل هذه الصناديق.

15 فرحات عباس ووسيلة سعود، "حوكمة الصناديق السيادية: دراسة لتجربة كل من النرويج والجزائر"، مجلة الباحث الاقتصادي، مج 3، العدد 4 . 18 (2019)

16 Salman Bahoo, Ilan Alon \& Andrea Paltrinieri, "Sovereign Wealth Funds: Past, Present and Future," International Review of Financial Analysis, vol. 67, no. c (2020), p. 9. 


\section{(9) الشكل}

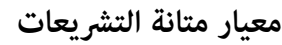

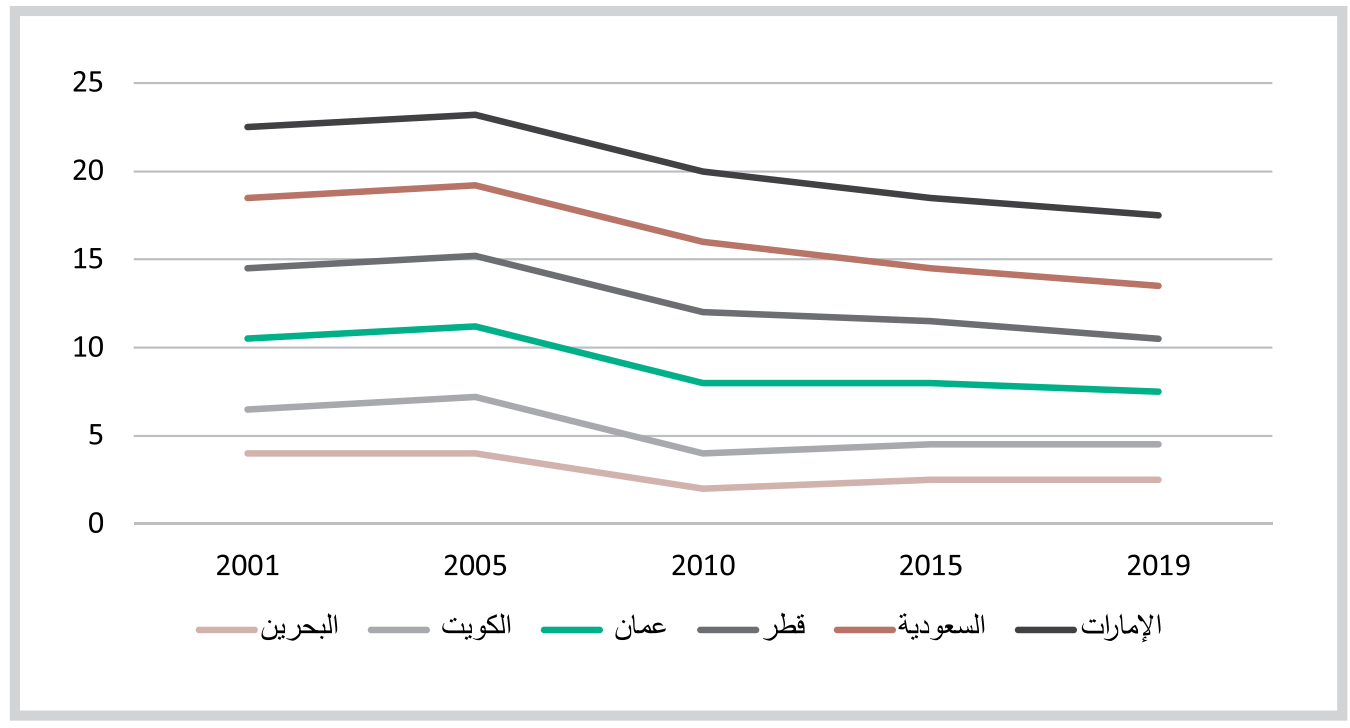

المصدر:

Political Risk Services (PRS), "Group International Country Risk Guide (ICRG)."

الشكل (10)

مؤشر فاعلية الحكومة في دول الخليج العربية (1996-2018)

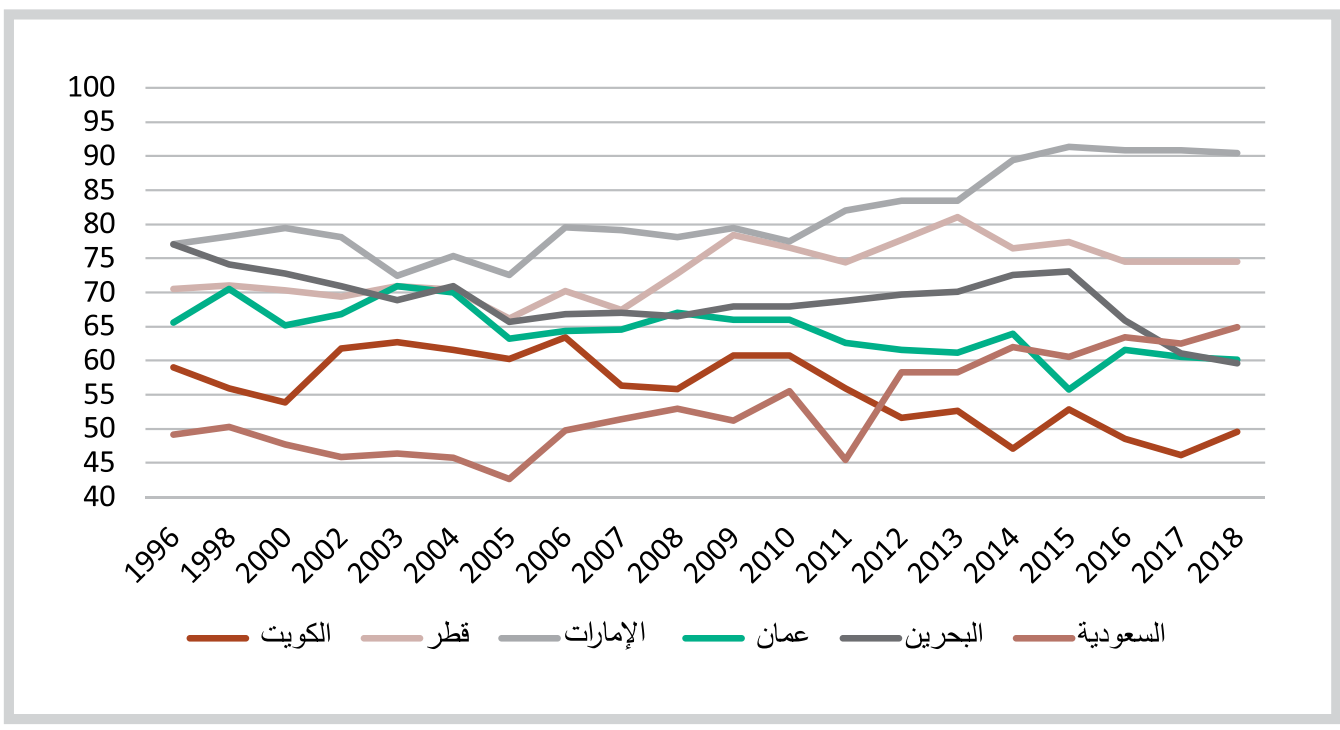

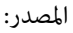

World Bank, World Development Indicators (WDI) 2020. 
وعند استخدام مؤشر آخر لقياس الحوكمة، وهو مؤشر فاعلية الحكومة Government Effectiveness كما في الشكل (10)، ويقيس مؤشر الحوكمة من ناحية فاعلية الأجهزة الحكومية في ممارسة أعمالها وسياساتها، فإن التراجع في مؤشر فاعلية الحكومة يظهر جليًا في ترتيب البحرين وعمان والكويت، ونسبيًا قطر، في حين ثمة ارتفاع نسبي لكل مهان

$$
\text { من الإمارات والسعودية (17). }
$$

واستنادًا إلى هذه النتائج، تبرز ضرورة تدعيم المهارسات المتعلقة بالحوكمة والشفافية للصناديق السيادية، وهذا

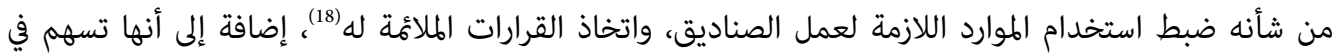
رفع مستوى شفافية الإجراءات المالية، وتحد من الفساد. إن وجود نظام قانوني للإفصاح والشفافية في التعاملات، لا سيما المالي منها، يضمن الانسيابية في توجيه العائدات النفطية مباشرة إلى الصندوق السيادي، ويقلل من احتمالات استغلال تلك الأموال من السياسيين والقائمين على الصناديق.

\section{3. درجة الانكشاف على الموازنة العامة}

نظرًا إلى الارتباط الوثيق بين الصناديق السيادية الخليجية، ومصدر قويلها المتمثل في العائدات النفطية، وكون

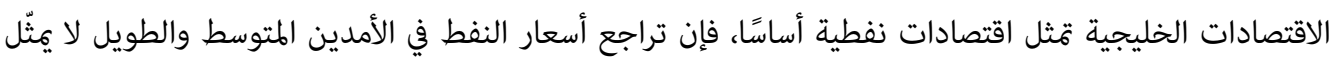

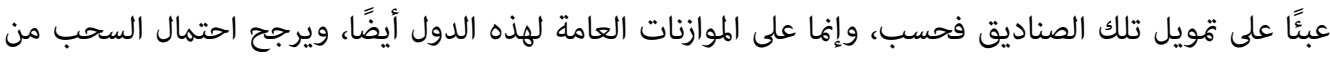

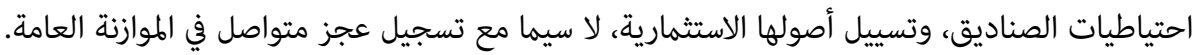
إن تفاقم عجز الموازنات العامة في دول الخليج يؤثر، بحدة، في ديمومة الموارد المالية واستقرارها، ويصبح الأمر أشد خطورة في ظل تأجيل استراتيجيات تنويع مصادر الدخل لاقتصاداتها، وحمايتها من أخطار تقلبات أسواق النفط. وعلى هذا الأساس، فإن معيار توازن الموازنة العامة، كما يوضحه الشكل (11)، يقيس درجة الأخطار المرتبطة بتوازن الموازنة العامة لدول الخليج. ويبين الشكل أن ارتفاع معيار توازن الموازنة العامة يعكس الانخفاض في الأخطار المتعلقة بالتوازن في الموازنة العامة. أما انخفاض المعيار فيشير إلى ارتفاع في الأخطار المتعلقة بتوازن الموازنة العامة. وكما هو موضح، فإن دول الخليج تعاني تقلبات عالية في معيار توازن الموازنة العامة، لا سيما في دولتي الإمارات والسعودية، وبدرجة أقل نسبيًا قطر وعمان والكويت. في حين تشهد البحرين تقلبًا أقل في معيار توازن الموازنة

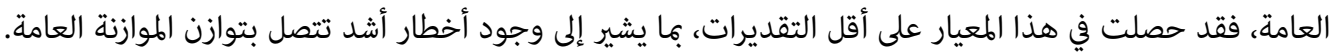
كما يلاحظ أن متوسط سعر النفط هو الذي يتحكم في تقلبات الأخطار المتعلقة بتوازن الموازنة العامة؛ وثمة ارتباط

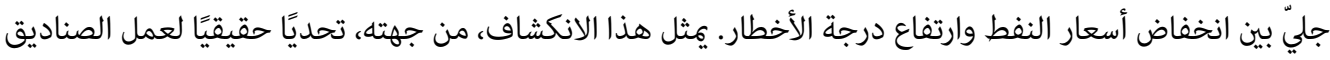
السيادية في دول الخليج، وقد يشجع السلوك الحكومي للسحب من الصندوق لتحقيق التوازن في الموازنة العامة، وربما يصل الأمر إلى تسييل جزء من الأصول الاستثمارية في الصندوق؛ لتغطية أوجه العجز المتوقعة.

17

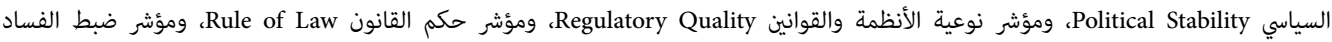
.Control of Corruption 18

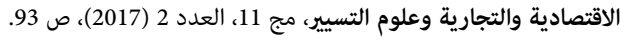


الشكل (11)

معيار توازن الموازنة العامة في دول الخليج العربية (2000-2019)

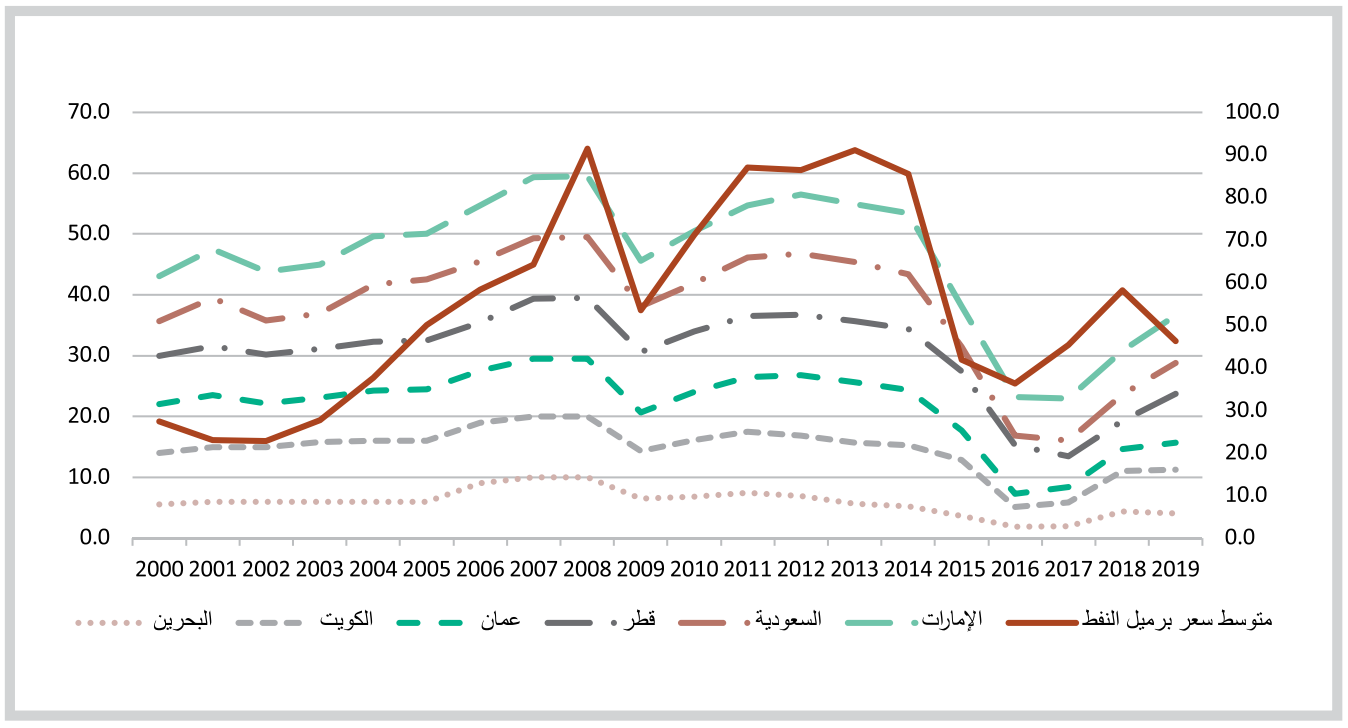

المصدر: Political Risk Services (PRS) Group.

الشكل (12)

مؤشر السيولة الدولية في دول الخليج العربية (2000-2019)

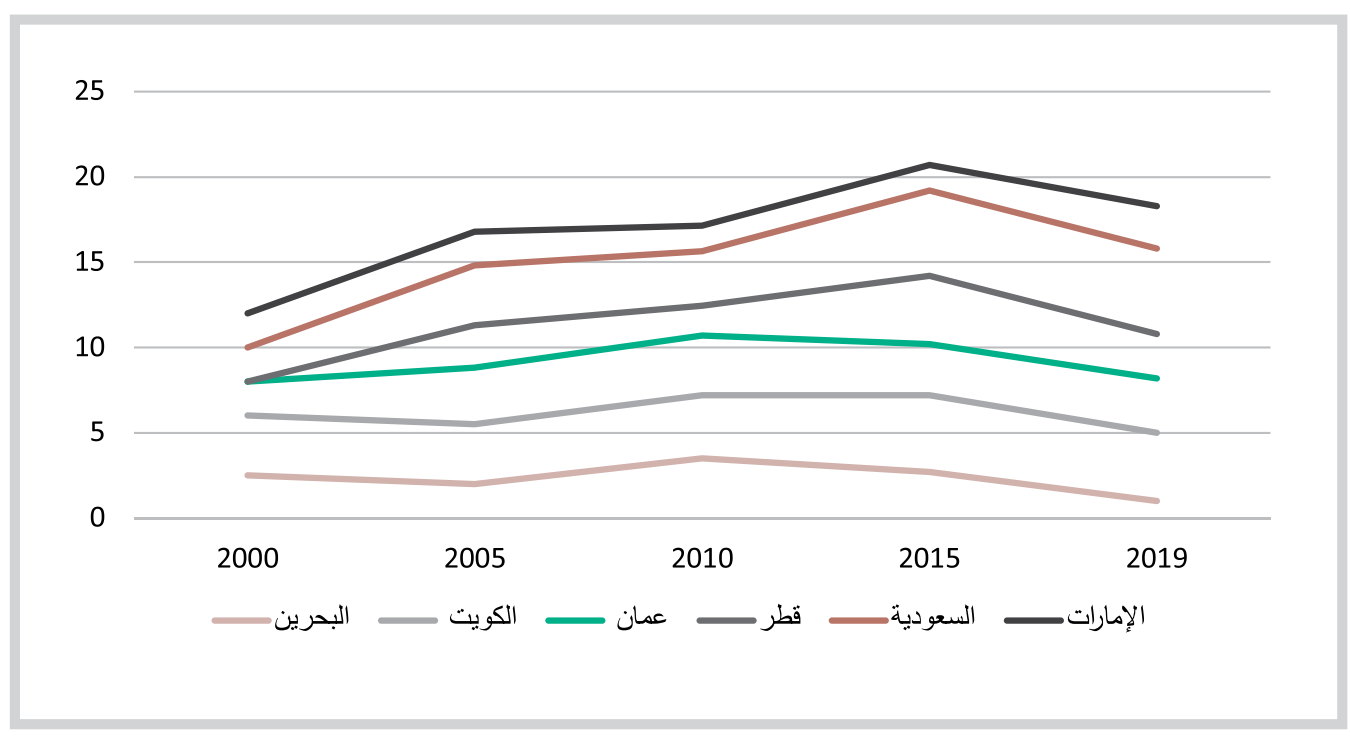

Ibid. : المصدر 
إن خلق قاعدة إنتاجية متنوعة في الاقتصادات الخليجية من شأنه تطوير عملية تنويع المحافظ الاستثمارية، بما فيها الصناديق السيادية (19). ونظريًا، فإن تراكم احتياطيات النقد الأجنبي المتحصلة من عائدات الصادرات النفطية يخلق سيولة كافية لتمويل الصناديق السيادية، وممارسة أوجه نشاطها. بيد أن التحول في نشاط الصناديق السيادية

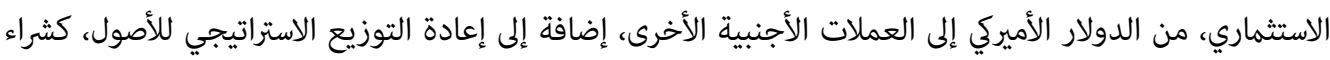

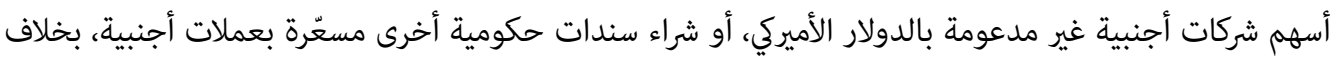

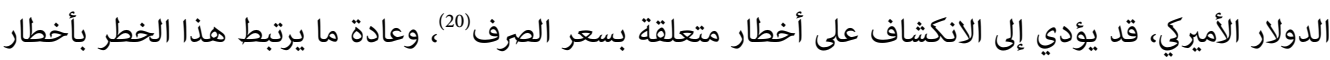
مماثلة في حجم السيولة الكلي في الدولة.

من هذا المنطلق، فإن مؤشر الأخطار المتعلق بالسيولة موضح في الشكل (12)؛ إذ إن ارتفاع المؤشر يعكس أخطارًا قليلة تتعلق بالسيولة، في حين أن تراجع المؤشر يعكس الارتفاع في تلك الأخطار. ومن خلال النظر في أداء مؤشر السيولة الدولية لدول الخليج، نجد ارتفاعًا ملحوظًا في الأخطار المرتبطة بالسيولة؛ فمؤشر السيولة الدولية أخذ في التراجع منذ عام 2015، لجميع دول الخليج، ومنذ عام 2010 للبحرين، ويعزى ذلك إلى التراجعات الحادة لأسعار النفط خلال تلك الفترة. وإذا ما استمر هذا الارتفاع في درجة الأخطار المرتبطة بالسيولة، فإن ذلك سيهدد الاستقرار المالي والاقتصادي لدول الخليج، ومن ثم سيحدّ من ممارسة أوجه نشاط الصناديق السيادية.

\section{5. تنافسية الاقتصاد المحلي}

يعتبر كل صندوق سيادي فريدًا من نوعه، من حيث المحفظة الاستثمارية التي يديرها واستراتيجياتها وأهدافها، ولكن يتمثل الغرض الأساس لكثير من الصناديق في المحافظة على الموارد المالية اللازمة لاستدامتها في الأمد الطويل للأجيال القادمة. بيد أن تحقيق الاستقرار الاقتصادي يعتبر هدفًا ضمنيًا تسعى الصناديق السيادية لتحقيقه في الأمدين القصير والمتوسط (21). ولا شك في أن الصناديق السيادية تؤدي دورًا محوريًا في تحقيق الاستقرار الاقتصادي للدول الهالكة لها. بيد أن استثمار تلك الصناديق، بما يحقق الأهداف المرجوة، مرتبط بدرجة عالية برفع مستوى القدرات التنافسية لتلك الاقتصادات، من خلال التركيز على بيئة الأعمال، ورأس المال البشري، والأسواق، وأخيرًا منظومة بيئة الابتكار. وقد اختير بعض المؤشرات التي تقيس تلك العوامل الأربعة، ذلك من خلال استخدام مؤشرات التنافسية الصادرة من منتدى الاقتصاد العالمي، ومقره جنيف، وتستخدم لتقييم مستوى الإنتاجية في الاقتصاد. فتنافسية بيئة

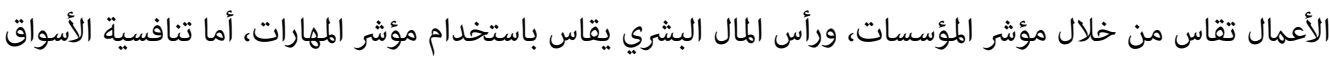
فيقيسها مؤشر النظام المالي، وأخيرًا تقاس منظومة بيئة الابتكار باستخدام مؤشر دينامية الأعمال. ويبين الجدول (4) مئرس

20 Adrian Blundell-Wignall, Yu-Wei Hu \& Juan Yermo, "Sovereign Wealth and Pension Fund Issues," OECD Working Papers on Insurance and Private Pensions, no. 14 (January 2008), p. 4.

21 Yael Selfin, Richard Snook \& Himani Gupta, The Impact of Sovereign Wealth Funds on Economic Success (London: Price waterhouse Coopers, 2011), p. 4. 
ترتيب تلك المؤشرات لعينة من الدول المالكة للصناديق السيادية القيادية عالميًا، وتضم دول الخليج وبعض مالكي أكبر الصناديق السيادية حجمًا، مثل سنغافورة وهونغ كونغ والنرويج وكوريا الجنوبية، وتشيلي.

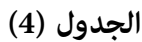

الترتيب العالكي لؤشرات التنافسية لعام 2019

\begin{tabular}{|c|c|c|c|c|}
\hline مؤشر دينامية الأعمال & مؤشر النظام المالي & مؤشر الههارات & مؤشر المؤسسات & الدولة \\
\hline 14 & 2 & 19 & 2 & سنغافورة \\
\hline 15 & 1 & 20 & 5 & هونغ كونغ \\
\hline 11 & 20 & 6 & 8 & النوويج \\
\hline 31 & 31 & 39 & 15 & الإمارات \\
\hline 25 & 18 & 27 & 26 & كوريا الجنوبية \\
\hline 47 & 21 & 47 & 32 & تشيلي \\
\hline 39 & 22 & 40 & 35 & قطر \\
\hline 109 & 38 & 25 & 37 & السعودية \\
\hline 48 & 37 & 52 & 38 & البحرين \\
\hline 56 & 59 & 38 & 39 & عمان \\
\hline 94 & 34 & 77 & 57 & الكويت \\
\hline
\end{tabular}

المصدر:

Global Competitiveness Report 2019: How to end a Lost Decade of Productivity Growth, World Economic Forum, 8/10/2019, accessed on 6/11/2020, at: http://bit.ly/3bsSBW5

من خلال الجدول (4) يمكن استخلاص بعض النتائج الأساسية المتعلقة بتنافسية صناديق دول الخليج، مقارنة بتنافسية الدول الأخرى المالكة للصناديق السيادية؛ فمؤشر المؤسسات يعكس جودة الأداء المؤسسي في الدول المعنية بسهولة

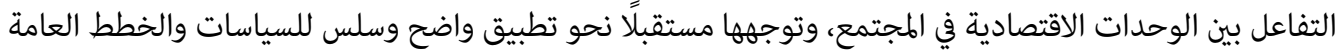

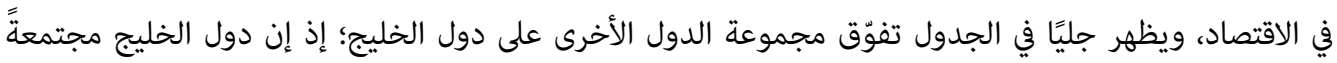

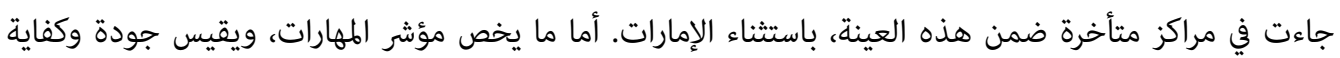

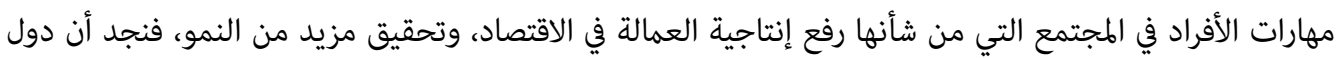

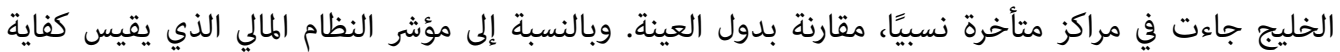

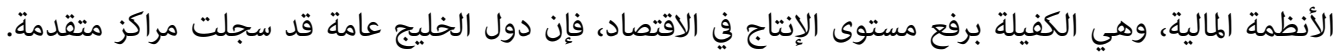
لكنها تظل أقل من المسجل لدى دول العينة من مالكي الصناديق السيادية القيادية. أما مؤشر دينامية الأعمال،

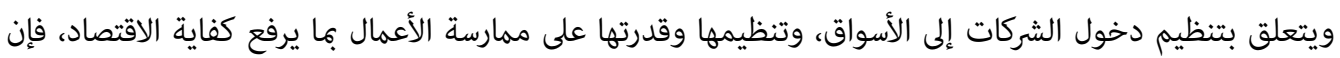
دول المجلس قد جاءت في مراكز متأخرة، وبفارق كبير عن أداء دول العينة من مالكي الصناديق السيادية القيادية.

وفي العموم، فإن الأداء الجيد لدول الخليج في مؤشر النظام المالي، والجيد نسبيًا في مؤشر المؤسسات، ما زال يحد منه تراجع مؤشرات رأس المال البشري؛ ويتطلب عمليات تحسين تنافسية الاقتصادات الخليجية في التنمية البشرية، 
وتحسين بيئة الابتكار ونظمه. من الضروري أن تعمل الحكومات لتدريب العمالة وتطويرها، وتحسين المهارات المكتسبة للخريجين، وإجراء إصلاحات تشريعية ومؤسسية واسعة، تضمن خلق بيئة أعمال مشجعة، فحاجة دول الخليج إلى إيجاد أصول حقيقية بديلة للمورد النفطي ضرورية؛ لتعويض التراجع المتوقع في الدخل القومي، ولكن هذا يتطلب إيجاد اقتصاد تنافسي قادر على زيادة تحسين رفاهية الأفراد، والمحافظة على معدلات فهو متوازنة، قادرة على خلق فرص العمل، واستقرار المستوى العام للأسعار.

\section{الخاتمة: نتائج وتوصيات}

تثير محدودية المعرفة بأنماط حوكمة الصناديق السيادية الخليجية، وبأهدافها الاستثمارية، وبتوزيع أصولها، قلق المستثمرين والمنظمات الدولية (22)، فالدور المفترض أن تؤديه صناديق الثروة السيادية في دول الخليج لحماية الاقتصاد أحادي الجانب، والمتمثل في زيادة الأصول الاستثمارية للصناديق، بما يعزز الاحتياطيات، ويراكم عوائد مستقبلية لمصلحة الأجيال المقبلة في مرحلة بعد نضوب النفط، ما زال أحد الجوانب الإيجابية لعمل الصندوق. لكن يكمن لعن لهن الجانب الآخر في حماية الاقتصاد الوطني، عبر تنويع الاقتصادات بالأساس، وهذا ما لم يتحقق في دول الخليج بما يكفي.

إن طبيعة الاستراتيجية الاستثمارية للصناديق السيادية، كما هي حال دول الخليج، تجعلها غير جادة في تحقيق

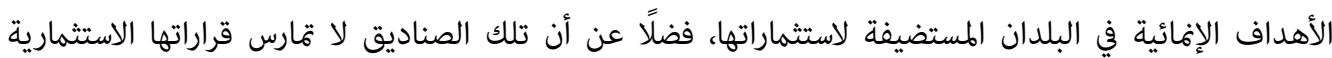

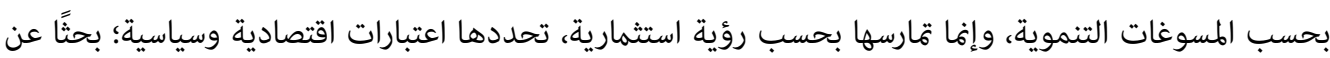
عوائد مالية تساهم في تنويع اقتصاديات تلك الدول (23)، إلا أن تدفقات تلك الاستثمارات قد تكون وسيلة تدعم

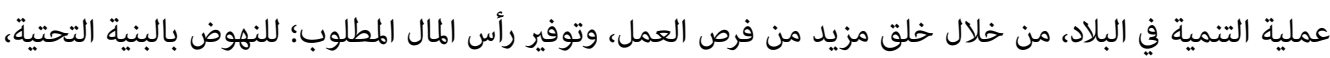

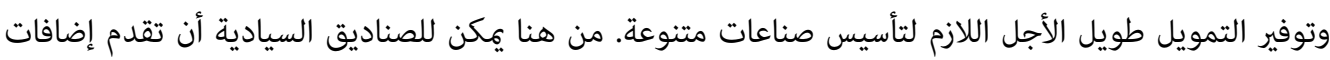

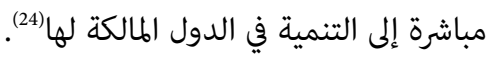

إن ما يميز حالة دول الخليج من غيرها من دول العالم أن لديها تراكثًا من المقارسات والخبرة العميقة في التعامل

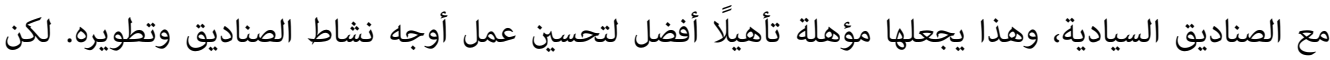
معظم تلك الصناديق الخليجية تشترك في قيود تحديد أولوياتها في استراتيجيتها الاستثمارية، فلا توجد معايير واضحة

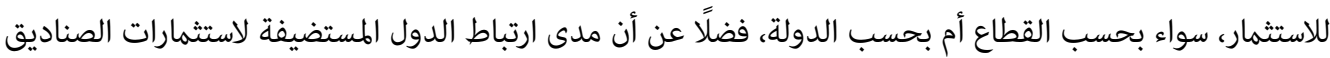

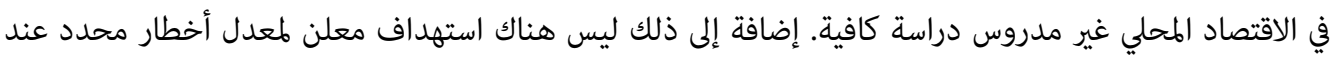

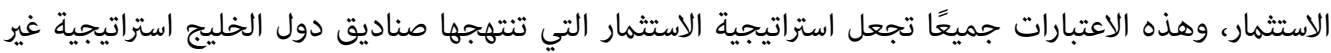
واضحة المعالم. وعلى الرغم من وجود تعاون بين كبار مالكي الصناديق السيادية وصناديق دول الخليج السيادية،

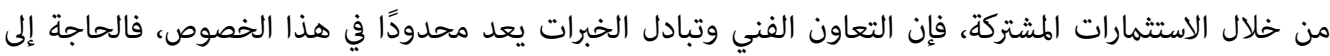

22 Jean-François Seznec, "The Gulf Sovereign Wealth Funds: Myths and Reality," Middle East Policy, vol. 15, no. 2 (2008), p. 100.

23

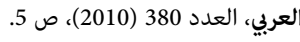

24 Javier Santiso, "Sovereign Development Funds: Key Financial Actors of the Shifting Wealth of Nations," Revue d'Économie Financière, Programme National Persée, vol. 9, no. 1 (2009), p. 304. 
تنظيم إدارة الصناديق السيادية، في ظل تزايد أعدادها تزايدًا ملحوظًا في الآونة الأخيرة، توجب تبادل الخبرات والتعلم من الممارسات، وكيفية الاستفادة من العوائد؛ لتحقيق هدف تنويع الاقتصادات المحلية في دول الخليج. فعلى سبيل المثال، نجد تعاونًا بين الصناديق السيادية في النرويج والولايات المتحدة الأميركية، في ما يتعلق بتبادل

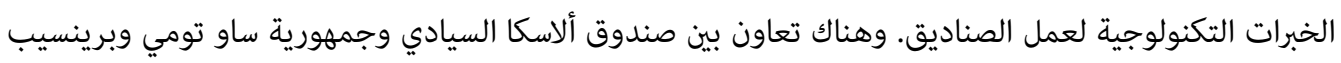
الديمقراطية São Tomé and Príncipe أيضًا، وساعدت النرويج جمهورية تيمور الشرقية في تطوير صندوقهات السيادي؛ لتستخدم نظامًا يدير عوائد النفط في الصندوق السيادي (25).

يعذّ خضوع الاستثمارات للتوجهات السياسية أبرز المخاوف التي تعرقل استثمارات الصناديق السيادية، لاسيما الخليجية منها. وتزداد هذه المخاوف في ضوء حجب الشفافية عن أوجه نشاط تلك الصناديق، على نحو يخلق مناخًا من عدم الثقة، ويعيق حرية توجيه تلك الاستثمارات الضخمة، سواء في الدول الصناعية أم في الأسواق الناشئة. ويؤثر هذا الوضع في تدفق رؤوس الأموال بينيًا، ومن ثم يؤثر في صافي الميزان الجاري لتلك الدول.

واستنادًا إلى ما توصلت إليه الدراسة من نتائج، نوجز التوصيات في النقاط الآتية:

1. التعجيل بإصلاحات سياسية واقتصادية في دول الخليج ضرورة ملحة، فهذه الإصلاحات تخلق بيئة ملائمة لتشجيع القطاعات غير النفطية، وتدفع نحو مزيد من الانفتاح الاقتصادي، وجذب إبل الاستثمارات. 2. لا تتحقق الإصلاحات إلا من خلال إرادة حكومية جادة، تستطيع استيعاب تكلفتها السياسية والاجتماعية،

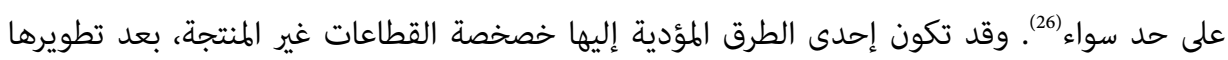

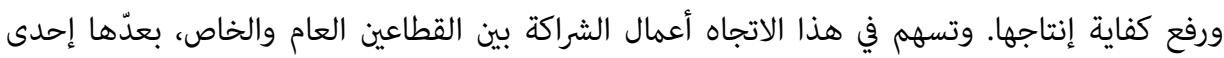
الطرق المهمة لرفع مستوى الاقتصاد، والتخلص من بعض المهارسات السلبية لكلا القطاعين؛ في سبيل تنفيذ إنداء

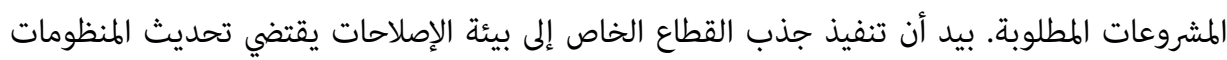

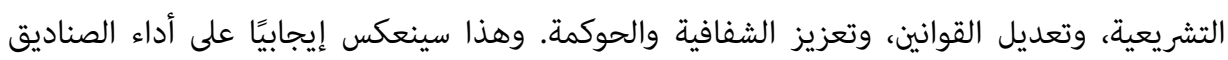
السيادية الخليجية، وعلى طريقة عملها، ويقلل الانعكاسات السلبية على التدفقات المالية للصناديق. 3. لا تقاس الجدوى الاقتصادية للصناديق السيادية من خلال العوائد المالية المتحصلة وحدها، وإفا من خلال

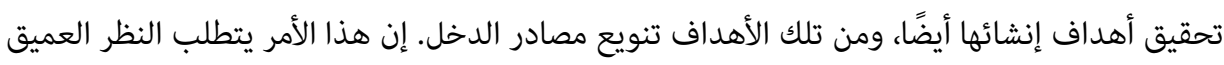

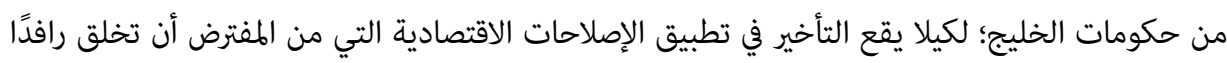

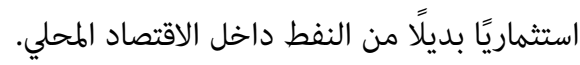
4. إن تبني الحكومات الخليجية سياسات تعزز الكفاية للنهوض برأس المال البشري، وممارسة الأعمال، من

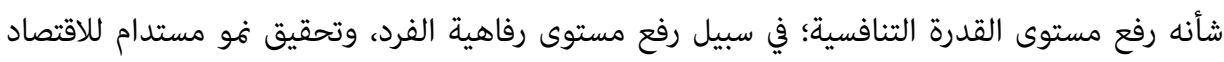

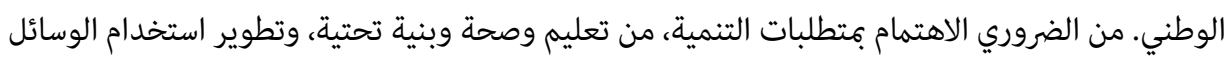
التكنولوجية الحديثة؛ لاستيعابها في مجال التعليم والتدريب أساسًا.

25 Alastair McKechnie, Managing Natural Resource Revenues: The Timor-Leste Petroleum Fund (London: Overseas Development Institute, 2013), p. 2.

26 Karen Young, "Sovereign Risk: Gulf Sovereign Wealth Funds as Engines of Growth and Political Resource," British Journal of Middle Eastern Studies, vol. 47, no. 1 (2020), p. 103. 
5. إن نظام توزيع الثروة الحالي في الخليج لا يعتبر ذا كفاية عالية، على الرغم من قدرة بعض بلدان

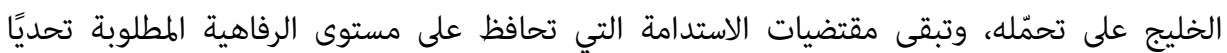
حقيقيًا لدول الخليج (27). 6. يجب أن يكون مسار المالية العامة متناسقًا مع الاستراتيجية الاستثمارية للصناديق السيادية، لا سيما من

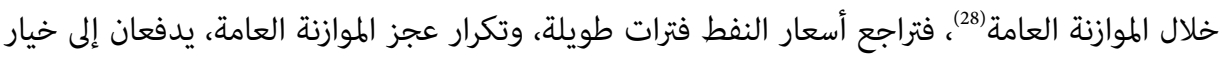

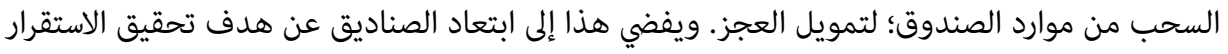

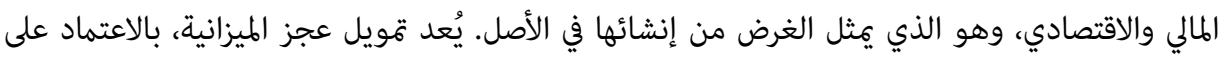

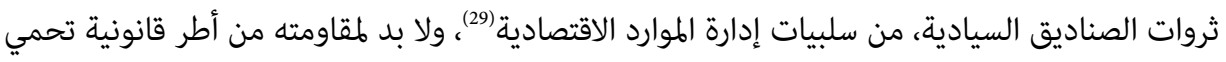
هذه الصناديق، وقواعد تعزز استقلاليتها عن الضغوط والسيطرة السياسية (30. 7. مة حاجة إلى تعديل الهياكل التنظيمية للصناديق القائمة، بما يتماشى مع مستجدات التعاملات المالية في

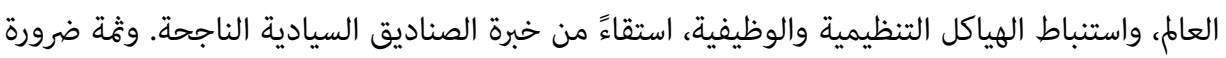

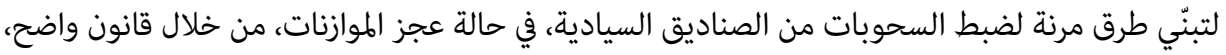

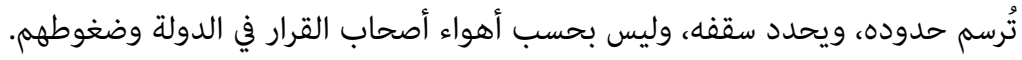

8. تجدر الاستفادة من التجارب الناجحة في التعامل مع الصناديق السيادية، كالصندوق النرويجي على

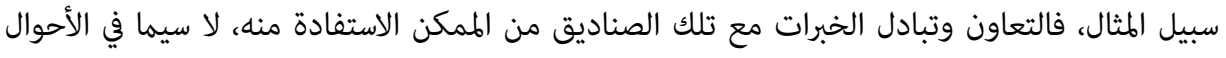

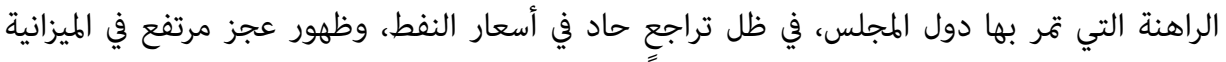
العامة لتلك الدول.

27 Steffen Hertog, "Reforming Wealth Distribution in Kuwait: Estimating Costs and Impacts," LSE Middle East Centre Paper Series, vol. 5, no. 28 (2020), p. 31.

$$
28
$$

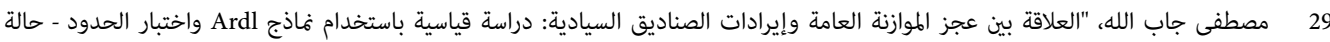

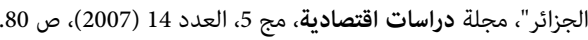

30 Raj Aggarwal \& John W. Goodell, "Sovereign Wealth Fund Governance and National Culture," International Business Review, vol. 27, no. 1 (2018), p. 83. 
بن عمارة، دليلة. "حوكمة صناديق الثروة السيادية واجهه لحوكمة الحكومات: دراسة مقارنة لجمموعة من صناديق الثروة السيادية". العلوم الاقتصادية والتجارية وعلوم التسيير. مج 11، العدد 2 (2017).

بو زيد، سفيان. "دور صناديق الثروة السيادية في ترشيد الإيرادات النفطية". مجلة البحوث السياسية والإدارية. مج 3، العدد 4 (2016).

بو فليح، نبيل ومحمد طرشي. "دور صناديق الثروة السيادية في إدارة عوائد النفط: صندوق الثروة السيادي النرويجي فوذجًا". مجلة رؤى اقتصادية. مج 7، العدد 12 (2015).

بو فليح، نبيل. "دور صناديق الثروة السيادية في تمويل اقتصاديات الدول النفطية: الواقع والآفاق مع الإثارة إلى حالة الجزائر. رسالة دكتوراه. كلية العلوم الاقتصادية وعلوم التسيير. جامعة الجزائر. الجزائر، 2011. جاب الله، مصطفى. "العلاقة بين عجز الموازنة العامة وإيرادات الصناديق السيادية: دراسة قياسية باستخدام فاذج Ardl واختبار الحدود - حالة الجزائر". مجلة دراسات اقتصادية. مج 5، العدد 14 (2007). حمادي، سعدون. "النفط والتنمية في الفكر الاقتصادي العربي: كيف طرحت قضية دور النفط في التنمية في الفكر الاقتصادي العربي". مجلة المستقبل العربي. العدد 380 (2010). دور صناديق الثروة السيادية في الاقتصاد العالمي: صندوق مصر السيادي بين دوافع التأسيس والأهداف. القاهرة: مركز مصر للدراسات الاقتصادية والاستراتيجية، 2019. سليماني، عبد الكريم. "دور صناديق الثروة السيادية في ترشيد الإيرادات النفطية العربية مع الإشارة إلى حالة أبوظبي". رسالة ماجستير. جامعة محمد خيضر. بسكرة. الجزائر، 2014.

عباس، فرحات ووسيلة سعود. "حوكمة الصناديق السيادية: دراسة لتجربة كل من النرويج والجزائر". مجلة الباحث الاقتصادي. مج 3، العدد 4 (2019).

قدي، عبد المجيد. الصناديق السيادية والأزمة المالية الراهنة. مجلة اقتصاديات شمال أفريقيا. العدد 6 (2010). المنيف، ماجد. "صناديق الثروة السيادية ودورها في إدارة الفوائض النفطية". مجلة النفط والتعاون الدولي. مج 35، العدد 129 (2009).

الأجنبية Aggarwal, Raj \& John W. Goodell. "Sovereign Wealth Fund Governance and National Culture." International Business Review. vol. 27, no. 1 (2018). 
Amar, Jeanne, Christelle Lecourt \& Valerie Kinon. "Is the Emergence of New Sovereign Wealth Funds a Fashion Phenomenon?" Review of World Economics. vol. 154, no. 4 (2018).

Asutay, Mehmet. "GCC Sovereign Wealth Funds and Their Role in the European and American Markets." Equilibri. vol. 12, no. 3 (2008).

Bahoo, Salman, Ilan Alon \& Andrea Paltrinieri. "Sovereign Wealth Funds: Past, Present and Future." International Review of Financial Analysis. vol. 67, no. c (2020).

Bazoobandi, Sara. (ed.). The New Regional Order in the Middle East. International Political Economy Series. Cham, Switzerland: Palgrave Macmillan, 2020. at: https://bit.ly/3p31id5

Blundell-Wignall, Adrian, Yu-Wei Hu \& Juan Yermo. "Sovereign Wealth and Pension Fund Issues." OECD Working Papers on Insurance and Private Pensions no. 14. (January 2008).

Braunstein, Juergen. "Domestic Sources of Twenty-first-century Geopolitics: Domestic Politics and Sovereign Wealth Funds in GCC Economies." New Political Economy. vol. 24, no. 2 (2019).

Gawdat, Bahgat. Sovereign Wealth Funds in the Gulf: An Assessment. Kuwait Programme on Development. Governance and Globalization in the Gulf States (16). London: The London School of Economics and Political Science, 2011.

Global Competitiveness Report 2019: How to end a Lost Decade of Productivity Growth. World Economic Forum. 8/10/2019. at: http://bit.ly/3bsSBW5

Grira, Jocelyn, Chiraz Labidi \& Wael Rouatbi. "Does Political Risk Matter for Sovereign Wealth Funds? International Evidence." International Review of Financial Analysis (2018). at: https://bit.ly/3rtd02O

Hertog, Steffen. "Reforming Wealth Distribution in Kuwait: Estimating Costs and Impacts." LSE Middle East Centre Paper Series. vol. 5, no. 28 (2020).

International Monetary Fund (IMF). "Sovereign Wealth Funds: A Work Agenda." Working Paper. Washington D.C. USA (2008).

Kimmitt, Robert. "Public Footprints in Private Markets: Sovereign Wealth Funds and the World Economy." Foreign Affairs. vol. 87, no. 1 (2008).

McKechnie, Alastair. Managing Natural Resource Revenues: The Timor-Leste Petroleum Fund. London: Overseas Development Institute, 2013.

Political Risk Services (PRS) Group, "International Country Risk Guide (ICRG)." 2020.

Ramady, Mohamed A. (ed.). The GCC Economies: Stepping Up to Future Challenges. New York: Springer, 2012. 
Santiso, Javier. "Sovereign Development Funds: Key Financial Actors of the Shifting Wealth of Nations." Revue d'Économie Financière, Programme National Persée. vol. 9, no. 1 (2009).

Selfin, Yael, Richard Snook \& Himani Gupta. The Impact of Sovereign Wealth Funds on Economic Success. London: Price waterhouse Coopers, 2011.

Seznec, Jean-François. "The Gulf Sovereign Wealth Funds: Myths and Reality." Middle East Policy. vol. 15, no. 2 (2008).

World Bank. World Development Indicators (WDI) 2020. Washington DC. USA, 2020.

Young, Karen. "Sovereign Risk: Gulf Sovereign Wealth Funds as Engines of Growth and Political Resource." British Journal of Middle Eastern Studies. vol. 47, no. 1 (2020). 